Images du travail, travail des images

$9 \mid 2020$

L'apprentissage et l'enseignement professionnel en images

\title{
Mémoires sensibles de l'eau. Apprentis marins sur l'île du Frioul dans les années 1950
}

Sense memories of water. Seafarer apprentices on the island of Frioul in the $1950 s$

Dominique Maillard

\section{OpenEdition}

\section{Journals}

Édition électronique

URL : http://journals.openedition.org/itti/443

DOI : $10.4000 /$ itti. 443

Éditeur

Université de Poitiers

Référence électronique

Dominique Maillard, « Mémoires sensibles de l'eau. Apprentis marins sur l'île du Frioul dans les années $1950 »$, Images du travail, travail des images [En ligne], 9 | 2020, mis en ligne le 01 septembre 2020, consulté le 14 avril 2021. URL : http://journals.openedition.org/itti/443 ; DOI : https://doi.org/10.4000/ itti.443

Ce document a été généré automatiquement le 14 avril 2021

Images du travail, travail des images 


\title{
Mémoires sensibles de l'eau. Apprentis marins sur l'île du Frioul dans les années 1950
}

\author{
Sense memories of water. Seafarer apprentices on the island of Frioul in the \\ $1950 s$
}

Dominique Maillard

1 Lorsqu'il s'installe sur l'île du Frioul dans les années $2000^{1}$, M. Barbaroux, capitaine au long cours (CLC) de la marine marchande, découvre de manière fortuite que l'île a hébergé, dans les années 1950, une école d'apprentissage maritime préparant aux métiers de la marine marchande. Sur place, il n'en reste plus aucune trace. Il conduit des recherches sur cette école et entreprend par ailleurs d'en retrouver d'anciens élèves. Par le biais d'un forum internet d'anciens salariés des Messageries maritimes, il est mis en contact avec un groupe d'anciens élèves de la promotion $1961^{2}$ qui communiquent via l'internet. Il leur propose de fêter sur l'île les 50 ans de leur promotion et d'inviter également les élèves d'autres promotions. Cette proposition le conduit à une correspondance plus ou moins soutenue avec certains d'entre eux et la relation interpersonnelle qui s'ensuit - mêlée de respect $^{3}$ et de confiance - sera essentielle dans la production d'un travail de mémoire collective.

2 Sur la quarantaine d'anciens contactés, plus de trente se retrouvent au Frioul en 2011 et à cette occasion « échangent » leurs souvenirs de l'École. Venus avec des évocations, images ou des formes plus tangibles de leur passage à l'École (cahiers, objets, photographies de l'époque, fascicule maritime), ils en reconstituent la trace. Ayant par ailleurs reçu plus d'une quinzaine de témoignages écrits, M. Barbaroux dépose une partie de ce matériau sur le site de l'association locale ${ }^{4}$ et sur son site personnel (Illustration 1). Sur fond d'une vue (très partielle) du Frioul et autour de l'insigne de l'école, il recompose alors - en empruntant au modèle du trombinoscope $e^{5}$ - une promotion d'élèves et crée, en quelque sorte, une "nouvelle " école fondée sur un réseau reconstruit de sociabilités et d'expériences. Ce dispositif ouvre en effet sur seize 
portraits d'anciens élèves où se mêlent évocations, images personnelles, description de la carrière ou d'autres éléments biographiques ${ }^{6}$.

Illustration 1 : une promotion d'élèves recomposée à distance

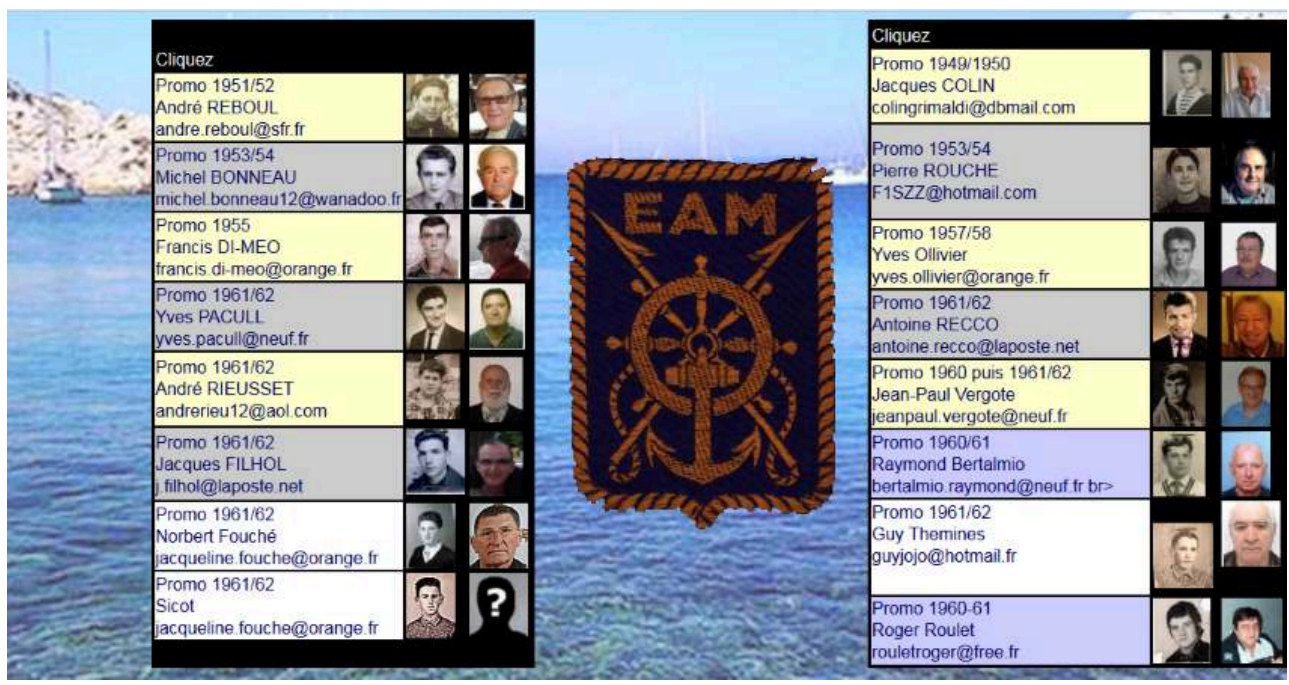

Ces portraits, comme « posés » sur la mer, donnent davantage une représentation en marins qu'en élèves.

Capture d'écran, http://andre.barbaroux.free.fr.

3 Ce matériau original invite à une réflexion croisant images de la formation et formation des images ${ }^{7}$. La démarche initiée par le capitaine Barbaroux a provoqué auprès des anciens élèves un travail de remémoration ou d'association mémorielle, travail par lequel l'école est ainsi reconstruite et vivante. Le cadre de cette mémoire collective nouvellement déployée vient ainsi «servir d'appui» aux différentes mémoires individuelles (Halbwachs, 1994 [1925]).

4 Malgré son caractère parcellaire et composite (orale, écrite, photographique, etc.) cette mémoire constitue une source riche pour l'histoire, toujours en cours, de l'enseignement professionnel maritime ${ }^{8}$. L'apprentissage maritime s'inscrit dans l'histoire sociale longue et complexe des gens de mer caractérisée par l'entrelacs des enjeux politiques et économiques des marines nationale et marchande. Organisé dans le but "d'enseigner à des élèves le fonctionnement d'un navire, de pêche ou de commerce, et les principes essentiels de la navigation » (Régnault, 1998), il recouvre une multiplicité de réalités sociales qui renvoient autant à la diversité des emplois et des activités préparées (autour de la pêche ou du commerce maritime) qu'à celle des territoires sur lesquels il s'est implanté. Les travaux fondateurs de Denis Biget sur la question $(2005,2010)$ ont mis à jour les conditions historiques et institutionnelles de son édification mais certains aspects de son fonctionnement ou de ses usages sociaux demeurent méconnus, notamment parce que les recherches entreprises ont surtout concerné les écoles des côtes bretonnes et normandes et se sont donc focalisées sur les activités de la pêche. Par ailleurs, l'intérêt pour les formations s'est davantage porté vers celles des officiers que des personnels d'exécution, en partie par manque de documents puisque, contrairement à la formation structurée des officiers, la formation des mousses et novices ${ }^{9}$ de la marine marchande n'a pas été organisée en dehors de l'apprentissage en mer (Cabantous, 1993, Kennerley, 2008). 
5 Poursuivant l'idée d'une exploration fine de la formation technique et professionnelle par les lieux de la formation (Lambert \& Lembré, 2017), cet article propose de décrire l'École d'apprentissage maritime (EAM) du Frioul du point de vue du sensible et de l'expérience des apprentis-marins. Il ne s'agit pas tant ici de documenter une histoire institutionnelle de l'école que d'interroger les formes mémorielles de réinterprétation qu'un ensemble composite d'images peut produire.

6 Pour tenir compte des effets de l'illusion biographique propres à ce type de matériau (Bourdieu, 1986), il convient de mettre celui-ci en perspective non seulement avec des éléments d'ensemble de l'enseignement maritime mais aussi avec certaines caractéristiques relatives à la situation marseillaise. La décennie 1950 est une période d'importantes transformations tant sociales qu'économiques, ces dernières ayant affecté largement le secteur de la marine marchande (Cassagnou, 2002). Alors même que ce milieu professionnel revendique un attachement fort aux principes fondateurs de la Marine, comment les témoignages actuels et images de l'époque permettent-ils d'apprécier la manière dont le système de formation entendait préparer les futurs marins aux changements à venir?

7 La première partie reviendra sur l'influence de la dimension corporatiste dans l'architecture globale et les pratiques de l'enseignement maritime. Cet aspect paraît d'autant plus important que la période étudiée, celle des années 1950, correspond à une structuration institutionnelle relativement récente, notamment pour l'activité de la marine de commerce. La deuxième partie envisagera les formes singulières que prendra le cadre national de l'enseignement maritime dans le contexte marseillais ; cet aspect sera appréhendé à la fois du point de vue de l'histoire spécifique et locale des formations maritimes mais aussi dans la situation du Marseille de l'époque et dans les images et témoignages des élèves. Dans la troisième partie, il s'agira de souligner l'importance, dans les mémoires individuelles et collectives, de la dimension spatiale de cet enseignement et de montrer comment l'île a façonné l'existence des élèves et construit des dispositions professionnelles par la rigueur du cadre et la discipline. Enfin, il conviendra d'interroger, dans une dernière partie, comment, par la formulation des souvenirs et le recours aux images, s'élabore un réenchantement de cet épisode biographique, très différent d'une histoire sur archives telle que peut en produire l'institution scolaire.

\section{Les années 1950 : le déploiement national d'un apprentissage maritime organisé}

8 Si l'histoire de l'enseignement professionnel maritime n'est pas totalement indépendante de celle de l'enseignement professionnel, elle n'en suit pas pour autant exactement les grandes dates fondatrices, le cadrage politique ou l'organisation administrative. La question de la formation professionnelle des marins et les débats qu'elle soulève à la fin du $\mathrm{XIX}^{\mathrm{e}}$ siècle et dans la première moitié $\mathrm{du} \mathrm{XX}^{\mathrm{e}}$ siècle cristallisent de manière exacerbée ${ }^{10}$ le statut du travailleur manuel et les mutations que le passage à une société industrielle impose à certains groupes sociaux. Les arguments mis en avant pour justifier un enseignement maritime concerne certes des points précis relatifs aux métiers de la mer (évolutions des méthodes de navigation du fait des nouvelles connaissances scientifiques, impératifs de sécurité en mer que ne garantissent plus les seules connaissances empiriques des marins, préparation d'une 
pêche industrielle qui se développe, etc.) mais il s'agit aussi d'intégrer les «populations maritimes » dans une société en devenir. Par ailleurs, les besoins de la marine militaire sont également présents dans les enjeux autour de la formation du marin. L'extrême diversité des intérêts partie prenante permet aussi de comprendre que l'enseignement maritime ait été élaboré dans un rapport plus ou moins direct au cadre national de la politique éducative.

D. Biget (2009) a montré que la création des EAM trouve certes ses origines dans l'organisation des écoles de pêches instituées en 1895 mais que le soubassement laïque et républicain au principe de ces écoles a été profondément modifié dans le projet de l'enseignement maritime tel qu'il s'institutionnalise en 1941. Contrairement à la volonté annoncée au sein de l'Éducation nationale de rompre avec les orientations prises durant les années de conflit (Robert, 2010) qui se traduit dans l'enseignement professionnel, entre autres, par une tension accrue entre les milieux patronaux et l'État (Troger, 1993), le modèle d'enseignement élaboré durant l'Occupation perdure du fait de ses assises corporatistes et d'une organisation administrative particulière de la formation qu'il convient à présent d'évoquer.

\subsection{Les bases corporatistes du modèle des EAM}

Créées en 1941, les EAM ont constitué dans le contexte de la Seconde Guerre mondiale les instruments d'un enseignement maritime organisé et institutionnalisé. Il s'agit de l'aboutissement d'un processus qui donne alors raison, contre les syndicats de gauche, aux idées défendues par les syndicats chrétiens, tenants du catholicisme social (Biget, 2005), voire aux représentants de l'Église catholique qui investissent aussi depuis les années 1930 la question maritime ${ }^{11}$. Le secteur des pêches et de la marine marchande, caractéristique des marchés du travail fermés, est de fait très sensible à la question de la formation qui constitue un soubassement de son fonctionnement (Paradeise, 1984). Pour autant, les lectures différenciées du monde maritime et des réalités sociales du travail qu'incarnent ceux qui parlent pour ou au nom des marins se traduisent par des modèles éducatifs divergents. C'est alors le modèle corporatiste qui prévaut pour penser le cadre de l'enseignement.

11 Le mouvement des Jeunesses chrétiennes maritimes notamment trouve dans la situation de guerre une opportunité pour mettre en forme ses idées en matière d'enseignement. En 1941, cette organisation obtient ainsi de l'État le financement et l'ouverture des premières écoles d'apprentissage maritime où seront délivrés les rudiments (pratiques et théoriques) de la navigation. La création de ces écoles croise alors plusieurs enjeux; elle apporte un élément de réponse à la situation des jeunes sans activité dans les régions portuaires de la zone occupée qui semble poser problème à l'occupant ; elle protège les jeunes du Service du travail obligatoire (STO) par le biais de certificats d'emploi et, dans le même temps, permet d'envisager le futur en préparant une main d'œuvre qualifiée pour les besoins de la profession. Le Département de la Marine marchande met en œuvre un apprentissage maritime dans une forme institutionnelle souple puisqu'il le finance mais n'en prend pas directement la responsabilité, confiant la gestion à une association privée. L'Association de gérance des écoles d'apprentissage maritime (AGEAM), déclarée à la préfecture des Bouches du Rhône $^{12}$, a pour but de "promouvoir et de gérer toutes les réalisations tendant à favoriser l'apprentissage maritime, éduquer, rééduquer, orienter et distraire les jeunes 
marins, en attendant que cette charge puisse être assurée par les corporations maritimes » (Journal officiel du 27 juillet 1941). L'association recrutera les instructeurs, professionnels qui alternent périodes d'activités professionnelles maritimes et périodes d'enseignement. Trois spécialités de CAP sont tout d'abord créées - celles de marinpêcheur, pêche et pont - auxquelles s'ajoutent plus tard celles de la machine et d'agent du service général (ADSG).

De 1941 à 1943, près d'une trentaine d'écoles sont créées; si elles fonctionnent de manière variable suivant les territoires, toutes se caractérisent par des conditions matérielles précaires ${ }^{13}$. Le manque de moyens - notamment l'absence d'ateliers dédiés se traduit par une tendance à la scolarisation. Les EAM sont critiquées par leurs détracteurs au motif qu'elles dispensent un enseignement insuffisamment professionnalisant (Biget, 2005, p. 49), ce qui leur fait courir le risque d'une intervention de l'Éducation nationale ${ }^{14}$, alors même que la spécificité du secteur mise en avant par la profession suppose l'autonomie de la formation aussi bien vis-à-vis de ce ministère que de celui de la Marine.

\subsection{Un certificat pour débuter sa carrière}

13 Face aux critiques dont elle fait l'objet et pour asseoir sa légitimité, l'AGEAM revendique auprès des pouvoirs publics le monopole de la gestion de l'enseignement maritime ${ }^{15}$ et cherche à rendre celui-ci obligatoire. Elle obtient gain de cause sur le premier point dès 1946. Sur le second, c'est la loi du 29 juillet 1950 qui, modifiant certains articles du code du travail maritime, réforme la loi de 1941 et conditionne l'emploi des jeunes marins à la détention d'un titre: "L'engagement avant l'âge de vingt ans à bord des navires de plus de 250 tonneaux de jauge est réservé aux titulaires d'un certificat d'apprenti marin délivré par les services de l'apprentissage maritime, placés sous l'autorité du ministre chargé de la marine marchande, ou d'un certificat délivré par ces mêmes services aux jeunes gens ayant fréquenté assidûment, pendant la durée d'une session de formation, une école d'apprentissage maritime, et aux jeunes gens ayant suivi assidûment, pendant la durée d'une année scolaire, les cours d'une école nationale de la marine marchande. » (Art. 116. JO du 30 juillet 195016)

14 Malgré la nécessité de reconstituer rapidement une marine marchande nationale, l'accès au métier conserve son fondement corporatiste. Une formation spécifiquement ajustée aux besoins de la profession ou encore la procédure d'inscription et le livret maritime (Illustration 2) en sont les préalables caractéristiques (Segrestin, 1985, p. 26-27). 
Illustration 2 : photographies des livrets maritimes de certains des anciens de l'EAM du Frioul

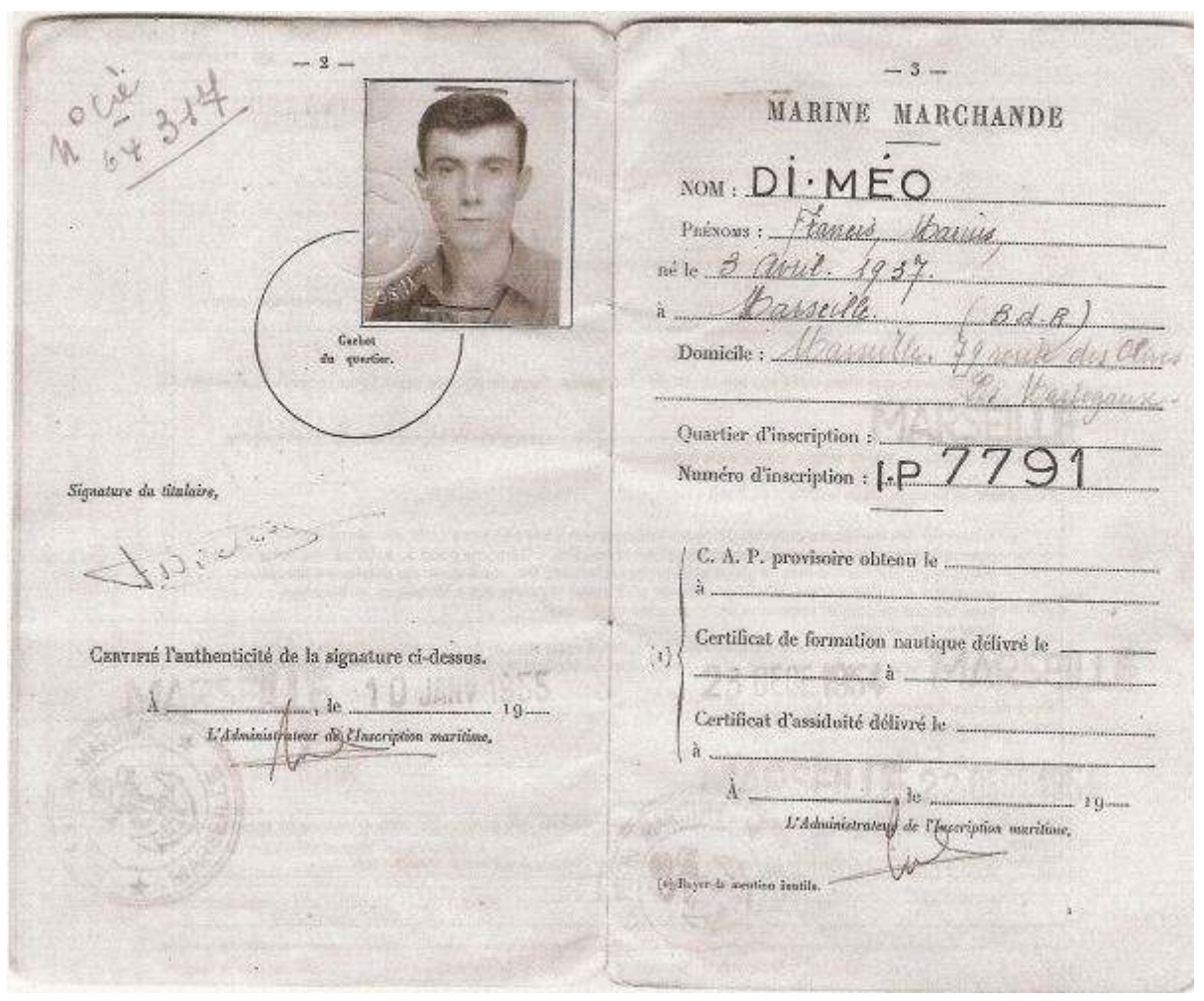

Coll. F. Di Méo

\section{R. Bertalmio}

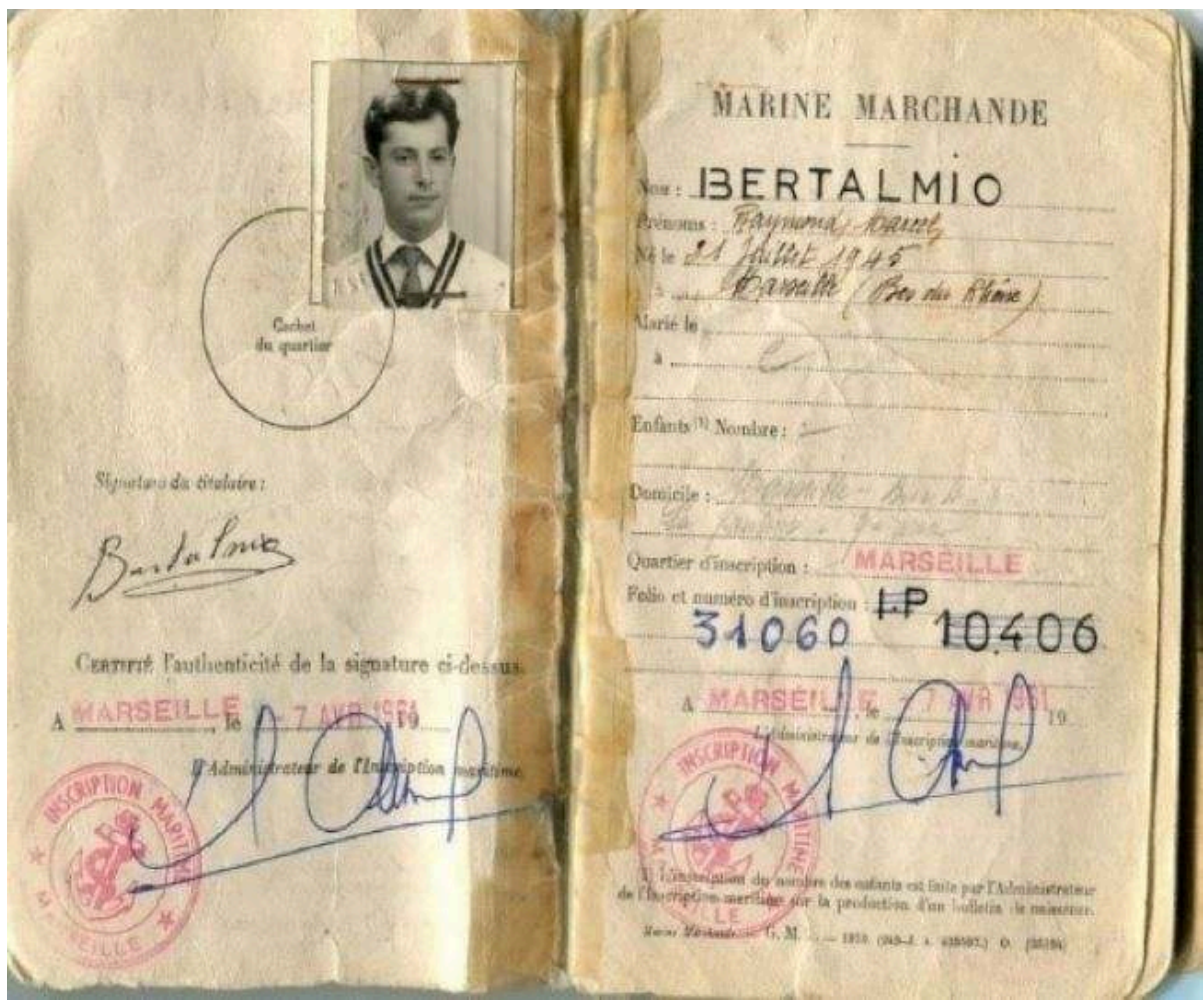

Coll. R. Bertalmio 


\section{J. Filhol}

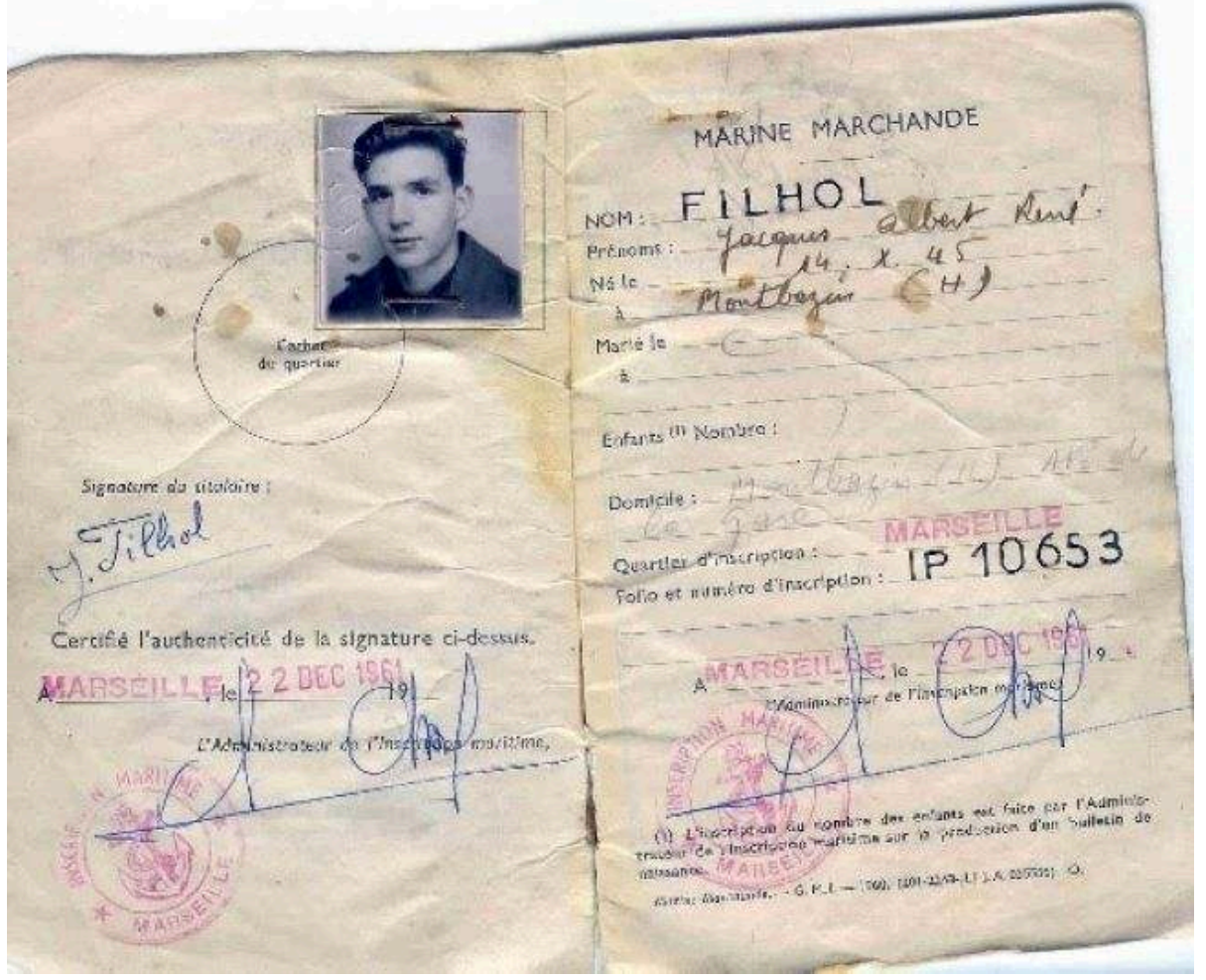

Coll. J. Filhol

\section{F. Stelmazach}

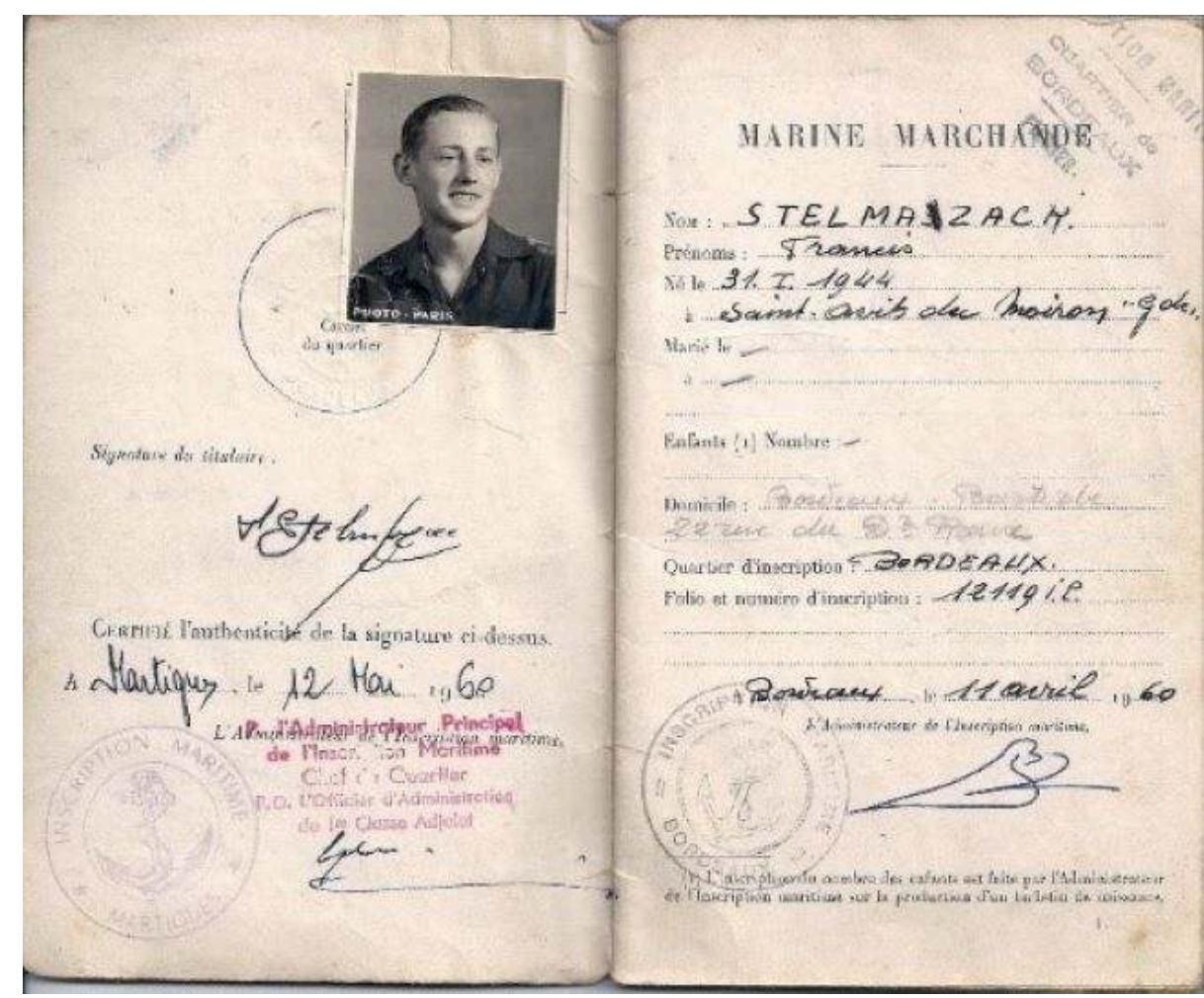

Coll. F. Stelmazach 
Véritable "pièce d'identité » du marin, le livret maritime contient des informations personnelles le concernant, tous ses embarquements mais aussi les titres attestant de sa qualification. Il n'est donc pas étonnant que le commandant Barbaroux ait recueilli un grand nombre de ces documents auprès des anciens élèves ${ }^{17}$.

D'autres exemples illustrent les mécanismes corporatistes de la formation: le public d'une part, le personnel et l'administration d'autre part. Face à l'afflux des demandes d'inscription dans les années de l'immédiat après-guerre ( $c f$. Illustration 4 ), la tutelle de l'apprentissage maritime, le ministère de la Marine, donne, à partir de 1951, priorité aux fils d'inscrits maritimes. Ceux-ci peuvent accéder sans examen aux écoles, à hauteur de $80 \%$ de l'effectif. Par ailleurs, des points de bonification leur sont attribués pour les épreuves psychotechniques. Pour les autres, le rang de classement à un examen organisé par un centre d'orientation professionnelle détermine leur entrée dans une école; tous doivent avoir préalablement réussi une épreuve d'éducation physique. Les cours sont gratuits mais les frais de scolarité (notamment l'internat) restent à la charge des familles. L'enseignement doit se rapprocher le plus possible de la manière de travailler du marin et l'expérience des "instructeurs» ou des «moniteurs» (professionnels navigants détachés de la Marine) servira de principe pédagogique.

Dans le contexte d'après-guerre et jusqu'au début de la décennie 1960, les campagnes de recrutement de la Marine nationale (Illustration 3$)^{18}$ ou le discours développé par la presse sur le renouveau de la marine marchande (Illustration 4) ont pu entretenir dans l'imaginaire juvénile la promesse d'un ailleurs ou d'une carrière réglée dans un cadre organisé. On retrouve d'ailleurs dans les témoignages des anciens l'expression de l'indétermination entre le militaire et le civil, certains ayant commencé l'EAM du Frioul ne finissent pas l'année et s'engagent dans la Marine nationale. 
Illustration 3 : promotion des métiers et de la formation de la Marine nationale au cours de la décennie $1950^{19}$

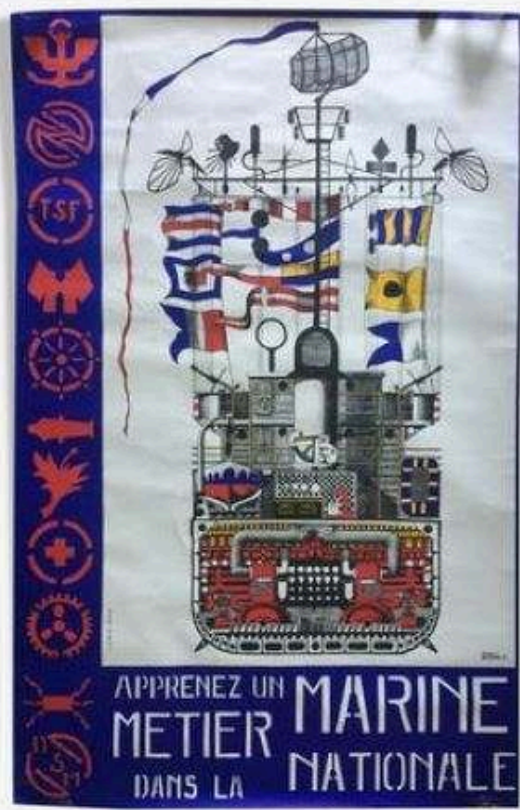

Illustration 3

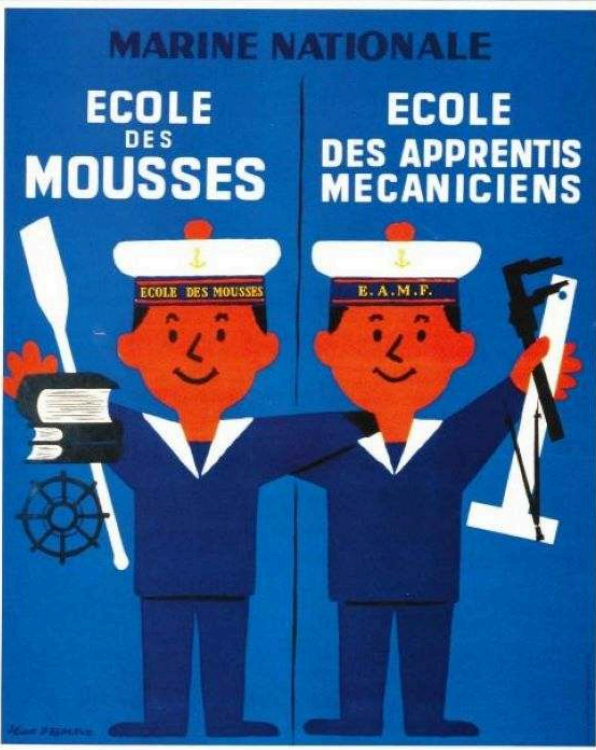

SESSION D'AVRIL : CLOTURE DES INSCRIPTIONS LE I2 JANVIER 1962

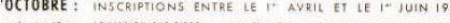

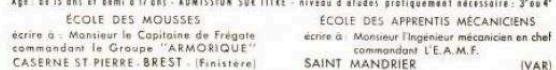




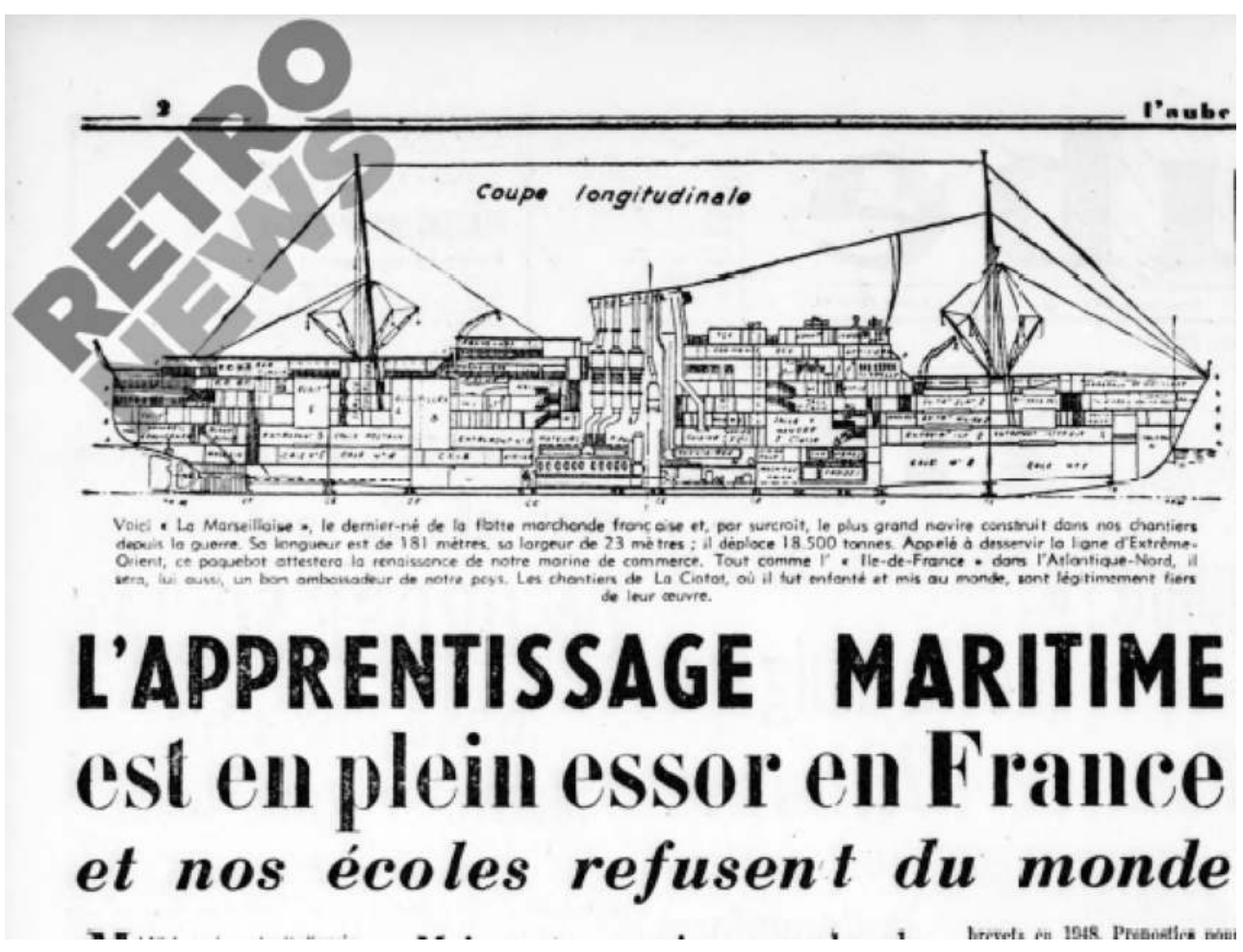

L'Aube, 4 Août 1949.

Source : Site Retronews. https://www.retronews.fr/

On remarquera dans les illustrations ci-dessus le caractère anatomique et organique de la représentation du navire.

Si cette présentation laisse suggérer que le secteur professionnel « s'ouvre » aux jeunes intéressés, elle montre aussi à ces derniers comment ils peuvent faire corps avec le bateau ${ }^{20}$.

En 1950, 17 écoles existent sur le territoire français. Le nombre d'écoles est proportionnellement plus important dans le Nord et la Bretagne. Sur l'ensemble des écoles, trois seulement sont situées dans la moitié sud de la France, à Bordeaux, Sète et Marseille. La répartition des écoles et des spécialités de formation est sans doute un compromis entre une offre déjà structurée sur le littoral et les particularités professionnelles et économiques des différentes zones côtières. L'école de Marseille avec celle du Havre sont les deux écoles qui dispensent les spécialités du pont, de la machine et d'agent du service général.

\section{L'EAM du Frioul, la singularité insulaire}

21 L'EAM a été installée au Frioul de 1949 à 1962 mais cet épisode n'est guère documenté ; le travail d'ensemble de Denis Biget sur l'enseignement maritime (2010) n'y fait pas mention, pas plus qu'on n'en trouve trace dans l'histoire de l'enseignement technique à Marseille (Barroero, 1995). Les sources écrites, orales et photographiques recueillies auprès des anciens élèves apportent bien sûr des informations sur le fonctionnement de l'École mais elles questionnent aussi la manière dont cette école, inscrite dans une politique nationale, intègre des dimensions locales sur lesquelles il convient de revenir 
à présent, notamment par les usages sociaux que l'offre d'enseignement maritime a contribué à façonner.

\subsection{Du bateau-école à l'île-bâteau, I'EAM dans l'histoire de l'enseignement maritime local}

22 L'histoire locale de l'enseignement maritime est essentiellement marquée, depuis le XIX ${ }^{\mathrm{e}}$ siècle, par des initiatives de la chambre de commerce de Marseille pour réaliser les ambitions de développement des élites économiques ${ }^{21}$. Sans approfondir outre mesure les projets et réalisations de la chambre (cf. Régaudiat, 2005), il faut néanmoins mentionner deux exemples qui de manière plus ou moins directe ont construit un contexte de réference pour l'école étudiée.

Avec l'École des Mousses, la chambre a contribué à former, de 1839 à 1901, une main d'œuvre pour les besoins en navigation des compagnies maritimes, sur le principe de la mise au travail des enfants « vagabonds » (Américi, 2002). Un bateau amarré devant la Mairie servait alors d'école pour l'ensemble de la formation de base du marin mais aussi de lieu de recrutement pour constituer les équipages. Les différents bateaux utilisés ont donné lieu à une imagerie abondante (cartes postales) qui a pu inscrire durablement la formation du marin dans l'espace local. L'utilisation (impropre) par certains anciens élèves de l'EAM du terme « d'école des mousses » confond peut-être le statut professionnel auquel ils ont accédé en sortant de l'école (compte-tenu de leur âge) et cette ancienne école marseillaise.

Le second cas reliant l'action de la chambre en matière d'enseignement maritime avec l'histoire de l'EAM concerne l'École Courbet. Fondée en 1901 par l'association de secours aux gens de mer de la Méditerranée, l'école est « destinée à venir en aide aux enfants de marins en les préparant aux professions de la marine marchande et aux écoles de la marine militaire ». Elle ne délivre pas de diplôme mais présente les élèves suivant leur âge et leur cursus au certificat d'études primaires, au brevet élémentaire, à l'école des apprentis marins de Brest, à l'École des apprentis mécaniciens de Lorient et de Toulon ou encore à l'École de Maistrance de Toulon. Les difficultés financières de l'école conduisent la chambre à accepter d'en assurer la gestion et le fonctionnement, ce qu'elle fait à partir de 1937. Ce faisant, la chambre ambitionne de mettre en œuvre, avec d'autres formations qu'elle finance déjà, un projet global et moderne de préparation aux professions maritimes (Régaudiat, 2005). Malgré le soutien des compagnies maritimes, l'État ne donne pas suite à la demande de reconnaissance de l'École. La décision en 1941 de créer des écoles d'apprentissage maritime limitera le périmètre de l'intervention de la chambre de commerce de Marseille au préapprentissage maritime. En revanche, les locaux de l'École Courbet, aménagés par la chambre pour y développer un enseignement de qualité (notamment par l'installation d'ateliers et l'acquisition d'équipements), servent à accueillir, à Marseille, la première école d'apprentissage maritime française (Illustration 5$)^{22}$. 
Illustration 5 : base nautique de l'École Courbet, futur emplacement de l'EAM

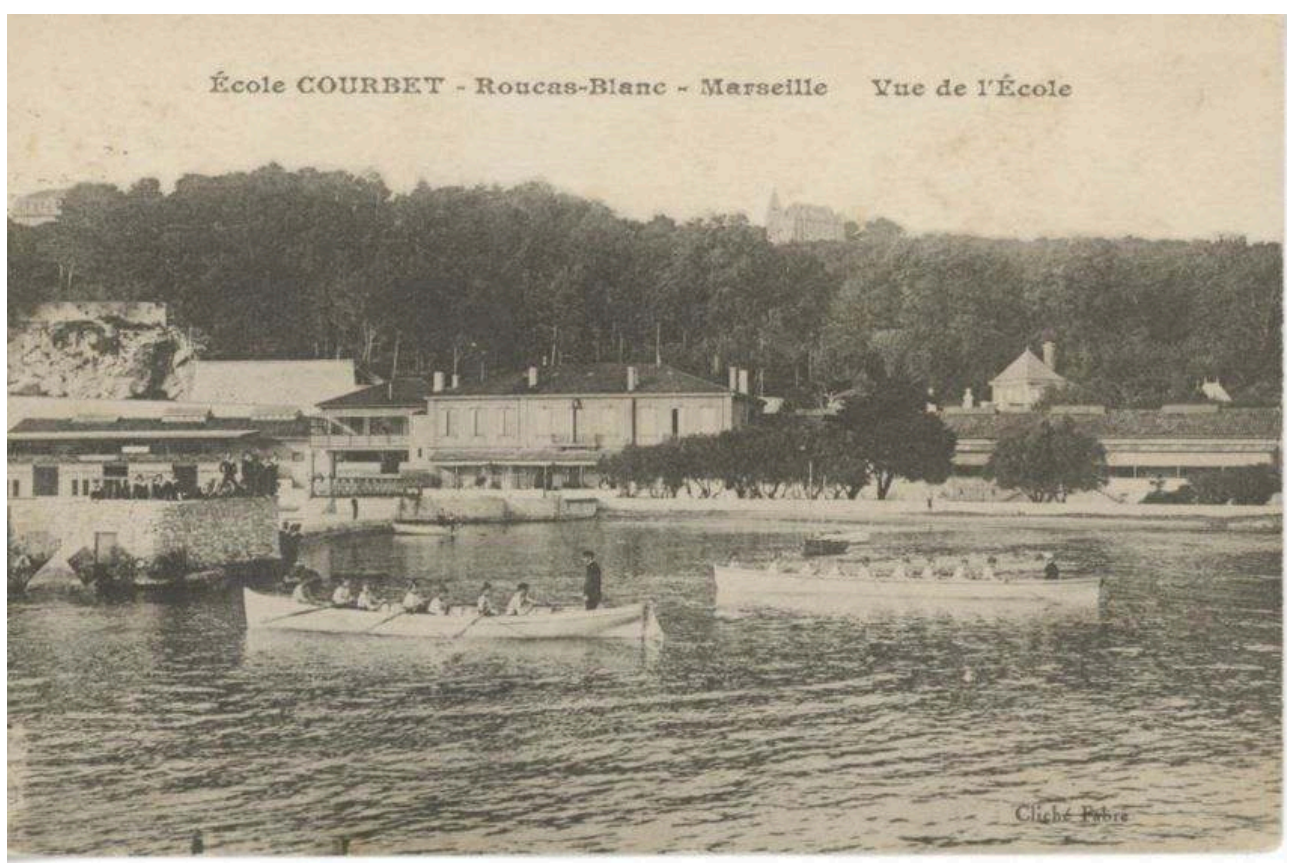

Source : Carte postale de l'École Courbet (nd). Coll. J. Vero.

L'EAM de Marseille y est toujours installée après-guerre et elle y reste jusqu'en 1948. Il $\mathrm{y}$ a en effet urgence à former et qualifier localement de jeunes marins. Malgré les destructions massives que Marseille et son port ont subies en 1944, un important soutien américain a permis que soient rapidement remises en service les infrastructures portuaires et que soit relancée l'activité maritime (Gras, 2010, 30). Les échanges avec les colonies et l'Asie - caractéristiques du modèle portuaire marseillais restent intenses même si le commerce se développe plus que le transport des passagers (Marnot, 2014).

Au tournant des années 1950, alors que d'une part les centres d'apprentissage dotés d'un statut (1949) finissent de structurer le système de l'enseignement technique et que d'autre part se trouve renforcé l'apprentissage maritime, les premiers locaux de l'EAM de Marseille sont sans doute jugés trop vétustes (cf. Biget, 2010 : photographie p. 80) ou insuffisants pour envisager d'y former des promotions nombreuses d'élèves. Toujours est-il que l'École installée au Frioul devient la plus importante des écoles françaises, accueillant entre 120 élèves et 150 à chaque session.

\subsection{Un caillou sur l'eau}

«Je ne sais pas si les autres élèves vous en ont parlé mais sur l'île, c'était les deux bâtiments de l'école, POINT BARRE, il n'y avait rien rien rien.» (NF_Promo 61/62_Entretien)

Le Frioul de l'EAM n'est pas alors la curiosité de l'espace marseillais où l'on se rend aujourd'hui en balade; c'est un lieu militaire sous contrôle de la Marine nationale. Sur place, quelques militaires gardent l'île et les marins du pilotage y sont stationnés. Aux conditions environnementales particulièrement arides - sécheresse, vents intenses, végétation rare - s'ajoutent les reliefs de l'occupation allemande et des bombardements alliés. Le caractère désolé du lieu (Photographie 1) est saisissant 
pour les élèves alors même que dans les témoignages, certains rappellent qu'ils n'avaient jamais vu la mer.

Photographie 1 : vue générale des îles du Frioul

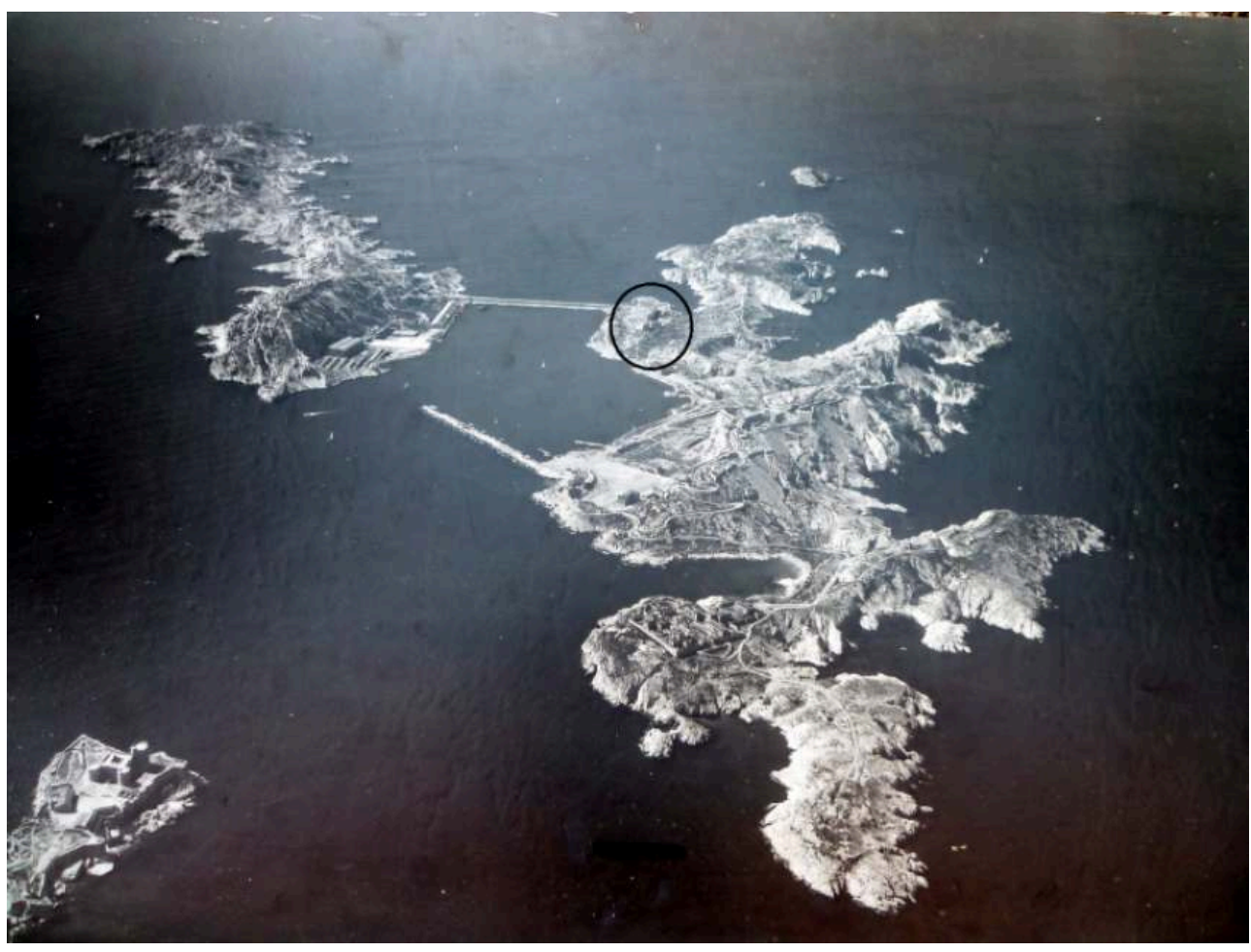

Coll. A. Barbaroux 
Photographie 2 : l'école et la chapelle

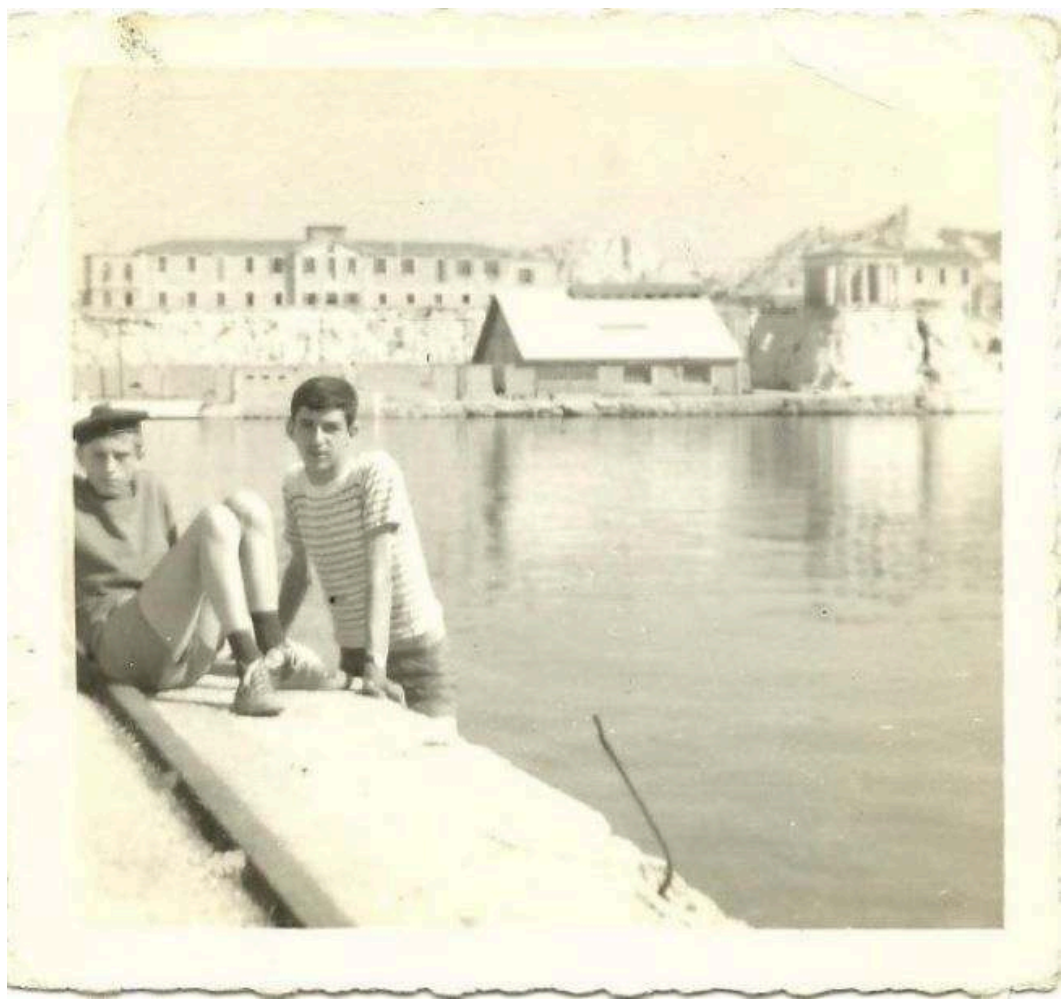

Coll. J. Filhol (Promotion 1961-1962)

Photographie 3 : bâtiment principal, retour du cours de natation

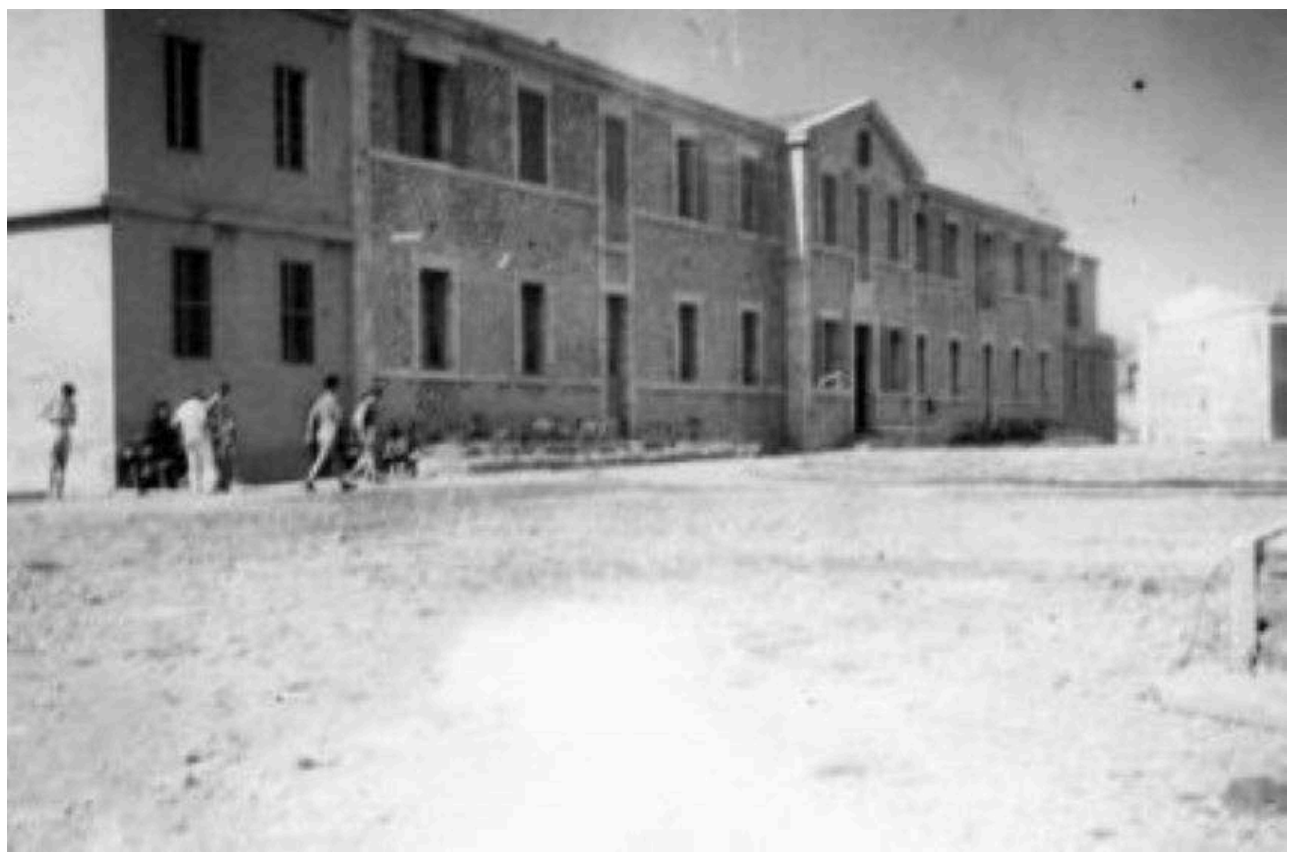

Coll. M. Bonneau (Promotion 1953-1954)

27 Si le bâtiment principal, où se trouvent les dortoirs, le carré des maîtres et le logement du directeur, présente une certaine majesté (Photographies 2 et 3), les ateliers (voileries et charpentage, ajustage, forge, matelotage) sont vétustes voire délabrés. Par 
ailleurs, les reliefs de la guerre (trous d'obus, débris divers) et la lumière crue tombant directement sur l'île donnent l'impression que les élèves sont les survivants d'un bateau échoué (Photographie 4).

Photographie 4 : sur l'île, restes et débris de l'occupation militaire

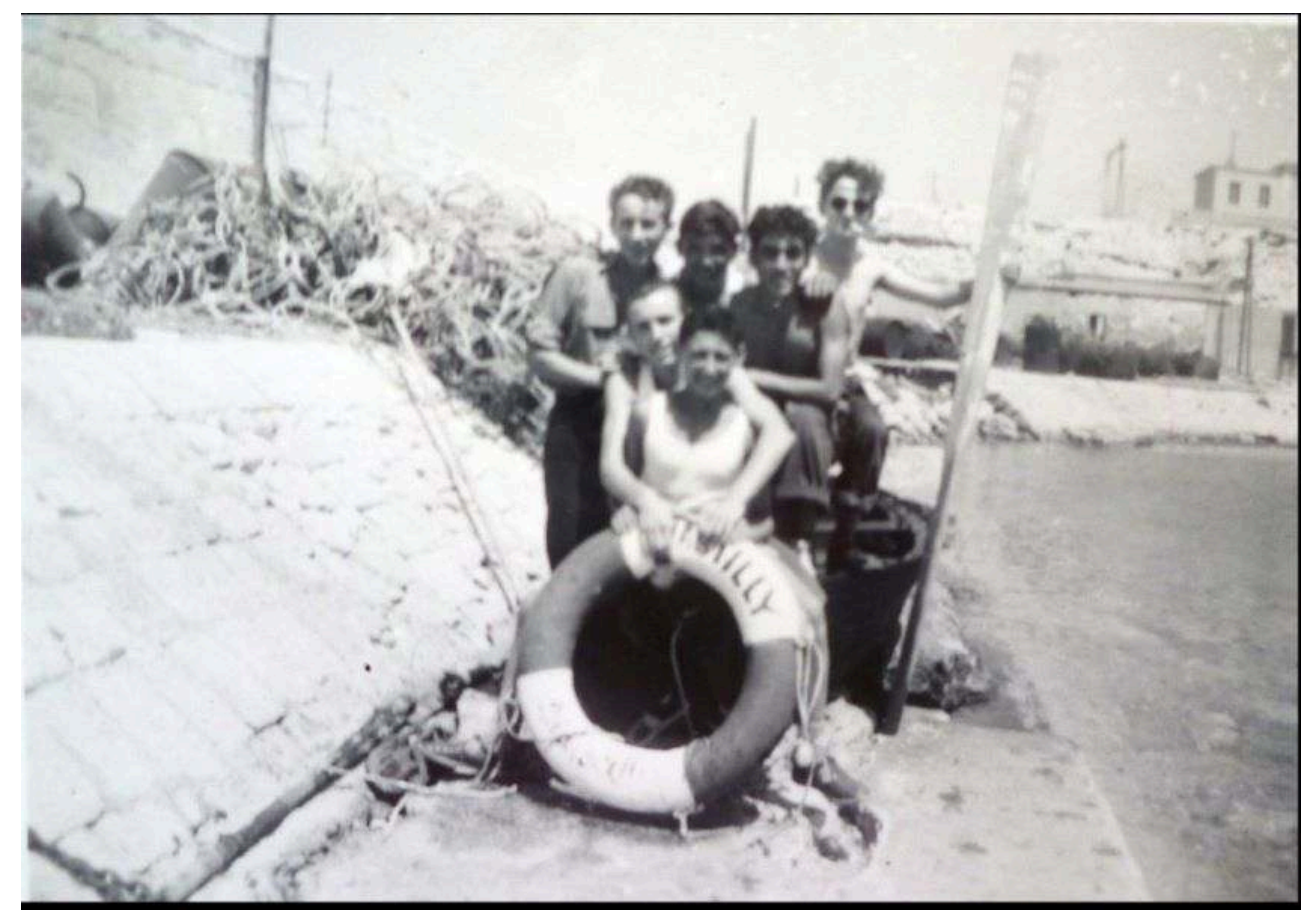

Coll. A. Reboul (Promotion 1951-1952)

Si l'on ajoute que l'île a longtemps servi pour la quarantaine, on peut avancer l'hypothèse qu'à travers l'expérience du Frioul se joue l'ambition de "remettre à flot " une marine, une économie ou plus globalement une société, en imposant à sa jeunesse une morale rigoureuse de vie et de travail, emblématique du projet de l'enseignement professionnel de l'époque (Troger, 2002, p. 62). Comment ces conditions d'enseignement particulières sont-elles restituées aujourd'hui par les élèves qui en ont livré images et témoignages?

\subsection{L'espace mémoire de l'île}

Les témoignages écrits sont de contenu très variable ${ }^{23}$ et l'ensemble montre de manière explicite que le rapport à l'École se décline de manière individuelle sur un large spectre qui renvoie dans une version minimale au titre scolaire ayant ouvert à la carrière de marin et à l'inverse, à une forme d'expérience totale ayant transformé radicalement une vie. De la même manière, les images associées à chacun des individus reflètent des aspects composites de la vie à l'École ou des manières de la représenter (Illustration 6) ${ }^{24}$. Comment caractériser les images communiquées par les anciens de l'École? Une partie correspond à des photographies prises à l'époque de la scolarité, une autre renvoie aux débuts de carrière, enfin une dernière est constituée de photographies, reproductions de différents objets personnels emblématiques du passage à l'École (livret maritime, cahiers, insignes, attestations, etc.) 
Illustration 6 : différents types d'images personnelles évoquant la scolarité (travail, statut ou réalisation personnelle)

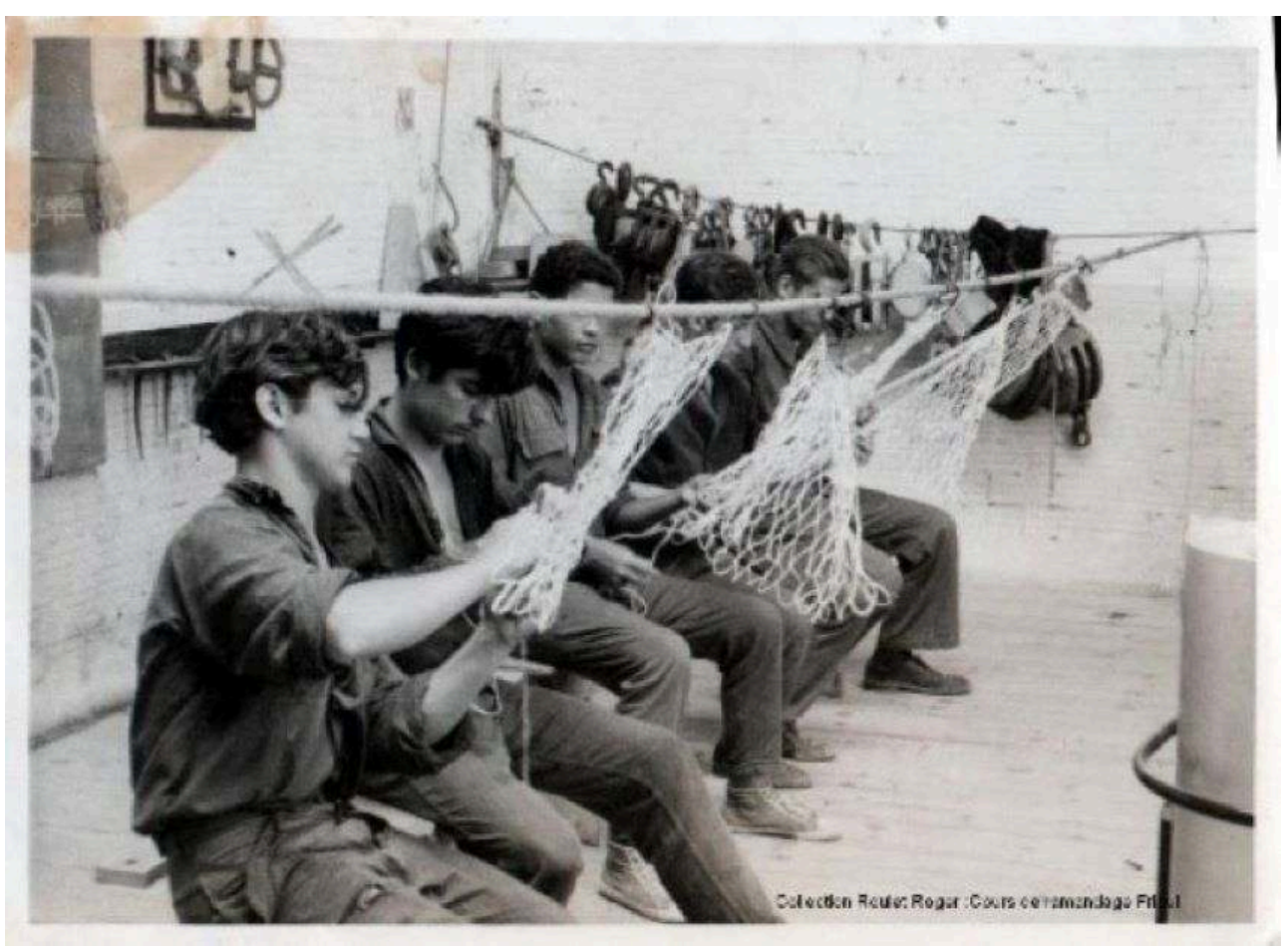

Coll. R. Roulet (Promotion 61-62)

Illustration 6

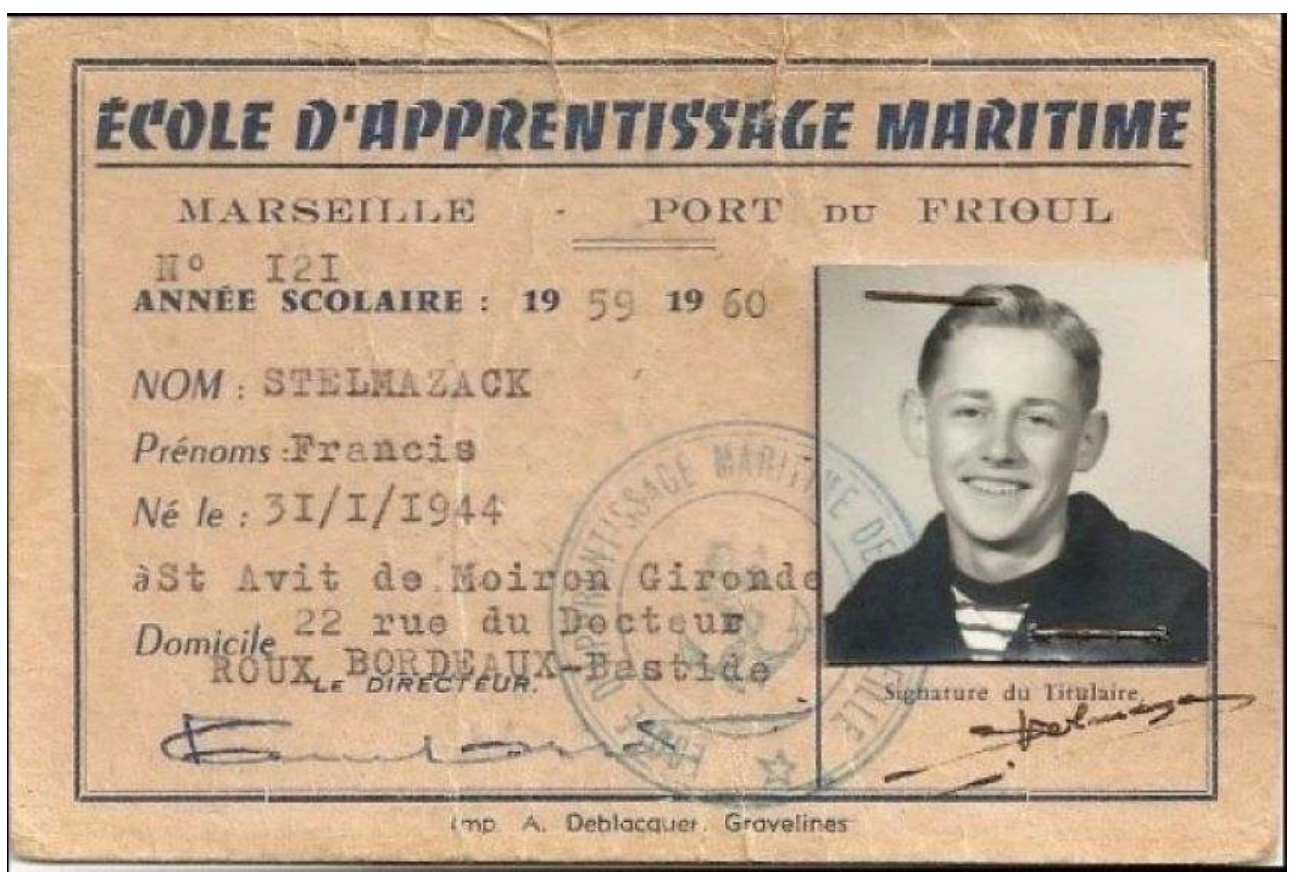

Coll. F. Stelmazach (Promotion 59-60) 


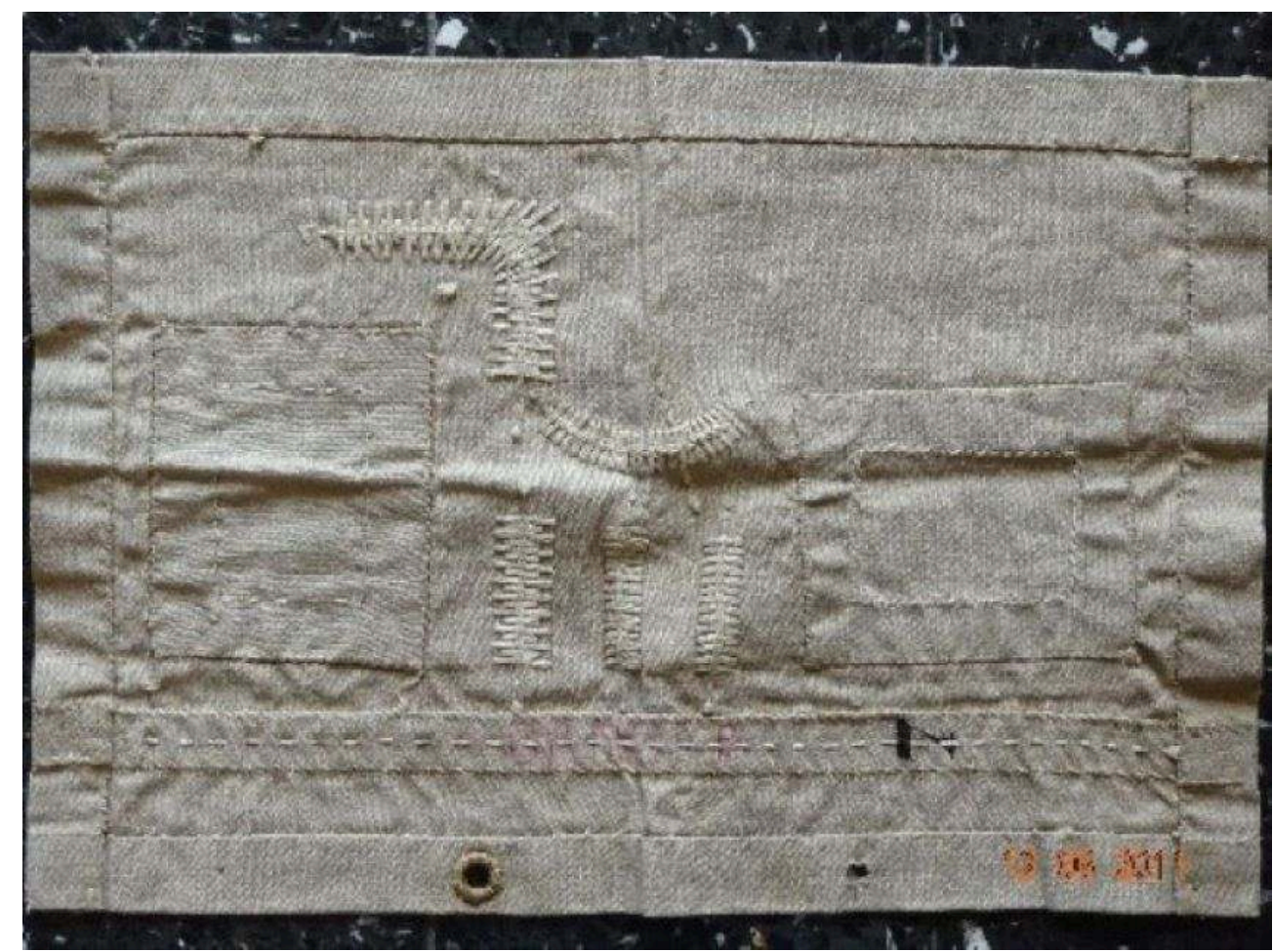

Coll. P. Gylbert (Promotion 61-62)

30 Parmi les représentations propres à la période de formation et dont les qualités techniques semblent indiquer qu'il s'agit d'une photographie amateur, quelques-unes montrent les bâtiments ou les équipements permettant la vie sur l'île (la vedette de ravitaillement ou le bateau de l'École). Toutes les autres mettent en scène les élèves, le plus souvent en groupe, dans des situations qui soulignent davantage les relations sociales du collectif que les temps où s'expérimentent les pratiques professionnelles ${ }^{25}$. Les élèves y posent dans quelques lieux emblématiques (la chapelle, le ponton, la digue), devant le mât du drapeau ou la camionnette de l'École. Ces points dessinent un périmètre relativement restreint que viennent quelque peu élargir les (rares) vues prises en mer ou dans l'espace public. Ils soulignent qu'au sein de l'espace déjà limité de l'île, celui dans lequel évoluent les élèves est encore davantage circonscrit et que cette sorte de confinement préfigure peut-être le huis clos extrêmement masculin de leur future activité maritime (Duval, 1998).

«Ces îles imprègneront mon esprit, elles contribueront vraisemblablement à forger mon caractère, insensibiliseront mes passions, étoufferont au plus profond de moimême les plus en plus rares foyers de révolte d'adolescent. " (YO_Promo 57/58_Témoignage écrit)

31 Comment le territoire du Frioul a-t-il contribué à préparer des jeunes gens aux dispositions professionnelles de leur futur métier? 


\section{Disciplines de l'apprentissage, apprentissage de la discipline}

Le matériau disponible pour évoquer l'École est, on l'a déjà signalé, un ensemble composite. La représentation iconographique tout à fait particulière s'exonère des conventions qu'on retrouve dans les documents institutionnels de l'école en général et de cet enseignement en particulier (cf. Biget, 2010) et ne rend quasiment pas compte des élèves en situation de formation stricto sensu (pas de prise de vue dans les salles de classe ou dans les ateliers). C'est donc essentiellement à travers les témoignages écrits et les entretiens qu'ont été analysés l'enseignement et les conditions de vie à l'École. En dépit des manières narratives et stylistiques propres à chacune des descriptions, la narration qu'ils font de l'École est relativement convergente et montre l'intérêt d'une analyse foucaldienne de l'institution scolaire, perspective relativement peu utilisée dans la sociologie de l'école (Dubet, 2014).

Dans La société punitive, Foucault (2013) envisage l'appareil scolaire, ses objets et ses manières de faire, comme un processus par lequel les élèves incorporent des exigences qui leur seront imposées ultérieurement par l'appareil productif ${ }^{26}$. Si l'on prolonge cette lecture, les techniques et formes de contrôle se trouvent alors redoublées par le fait même que l'École doit transmettre les dispositions professionnelles propres à des organisations disciplinaires, celle de la marine marchande en filiation directe avec la Royale et l'armée. Le principe pédagogique repose sur un recouvrement presque total entre une série de gestes appris aux élèves et ceux qui seront reproduits professionnellement, ces gestes devant se déployer dans un cadre lui aussi fortement contraint. Parmi les différents éléments qui caractérisent le modèle, seront davantage détaillés d'une part, la manière dont se déploient concrètement les aspects de contrôle de l'espace et de l'activité d'apprentissage et d'autre part, les instruments de la discipline.

\subsection{Le contrôle de l'espace}

Le rituel des couleurs ou la double affectation du lieu du repas et de la nuit illustrent la manière dont le contrôle de l'espace s'opère dans le quotidien des élèves au point d'en naturaliser les règles.

«C'était pas l'armée mais c'était quand même assez sévère, on était à mi-chemin, parce que ... on montait les couleurs le matin. [...] C'était normal, c'était la logique, donc pour nous, faire le salut le matin ... on n'était pas à l'armée mais c'était comme ça, c'était la marine marchande, mais quand même la marine marchande a quand même des règles... » (ARi_Promo 61/62_Entretien). 


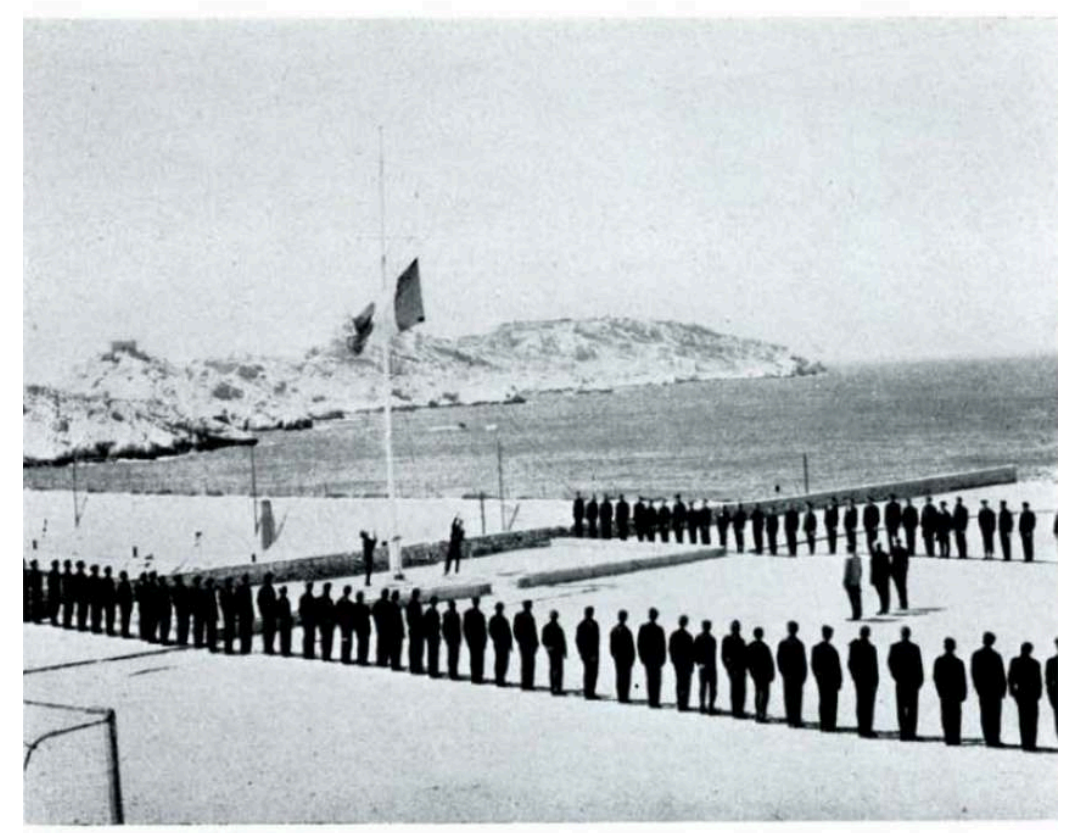

Les élèves de l'E.A.M. de Marseille-Frioul.

The students of the school of Marseilles-Frioul.

Source : Revue Sillage, $n^{\circ} 6$ et $7, \mathrm{nd}^{27}$

« La vie s'organisait entre l'envoi des couleurs dès l'aube, et le salut au drapeau au coucher du soleil. »(YO_Promo 57/58_Témoignage écrit)

Avec cette formule elliptique et imagée, la journée et la vie se confondent; le drapeau organise une circularité de l'existence mais il vise aussi à s'inscrire comme le point d'horizon symbolique du marin français. Le pavillon est hissé quotidiennement à 8 heures; cette activité permet ainsi l'inspection de l'ensemble des élèves, elle est un moment de vérification de l'unité du collectif mais aussi de la distance qui doit séparer chacun de ses membres. Contrairement à l'impression que donne la photographie $5 \mathrm{ci}$ dessous, les élèves ne revêtent pas un uniforme mais le directeur de l'École avait cherché à distinguer son établissement en exigeant une tenue réglementaire ${ }^{28}$ :

«On avait une tenue, alors on nous avait demandé, je me souviens que mon père était allé m'acheter une sorte de blouson bleu, il fallait qu'on soit en bleu. Ce n'était pas un vrai uniforme mais il fallait que la couleur bleue soit dominante.» (ARi_Promo 61/62_Entretien) 
Photographie 5 : la tenue réglementaire ${ }^{29}$

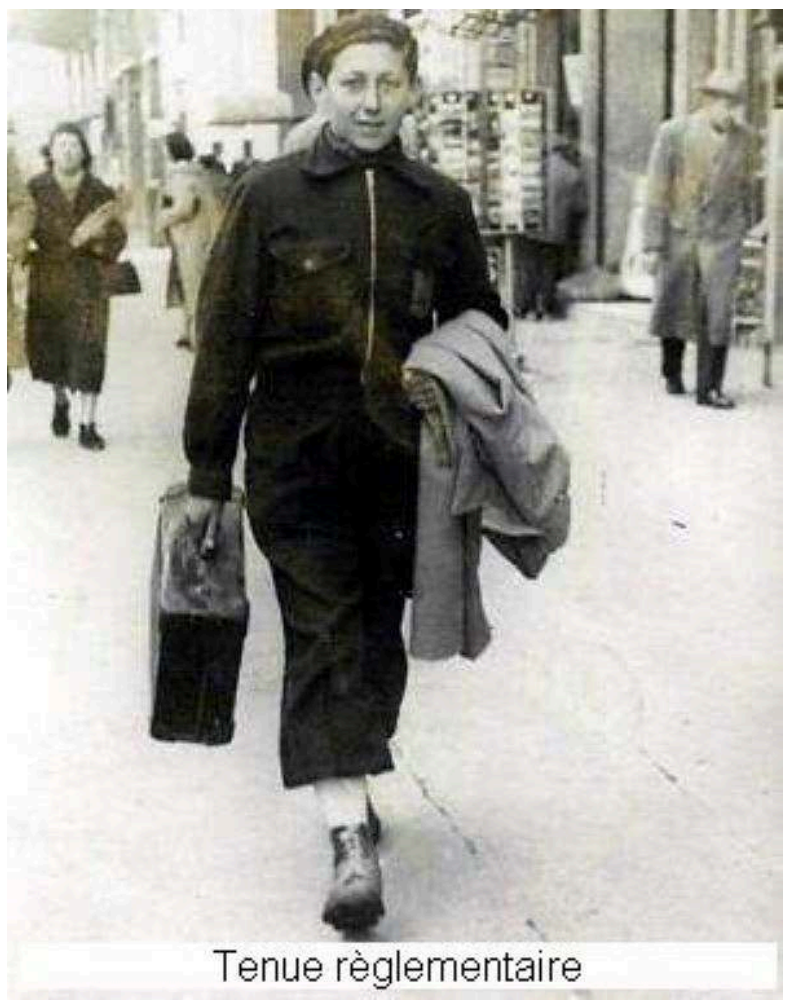

Coll. A. Reboul (Promotion 1951-1952)

Le second exemple retenu concerne l'espace que les élèves utilisent alternativement comme dortoir et comme réfectoire. Par comparaison avec d'autres écoles maritimes de l'époque, seule l'École du Frioul utilise des hamacs pour le couchage des élèves. Là encore, on recourt à l'argument de la tradition de la marine à voile pour justifier une telle martialité. Chaque élève se voit attribuer une place. Outre le fait que cette organisation se réalise avec un minimum de moyens, elle permet l'alignement de tous les pensionnaires, empêche l'intimité, limite l'espace où peuvent être rangés les effets personnels et contrarie - dans une moindre mesure - les velléités de sorties nocturnes. Certes, le hamac renvoie à l'image traditionnelle de la marine à voile mais surtout il maintient le corps en place. 
Illustration 8 : repas et dortoir dans le même espace

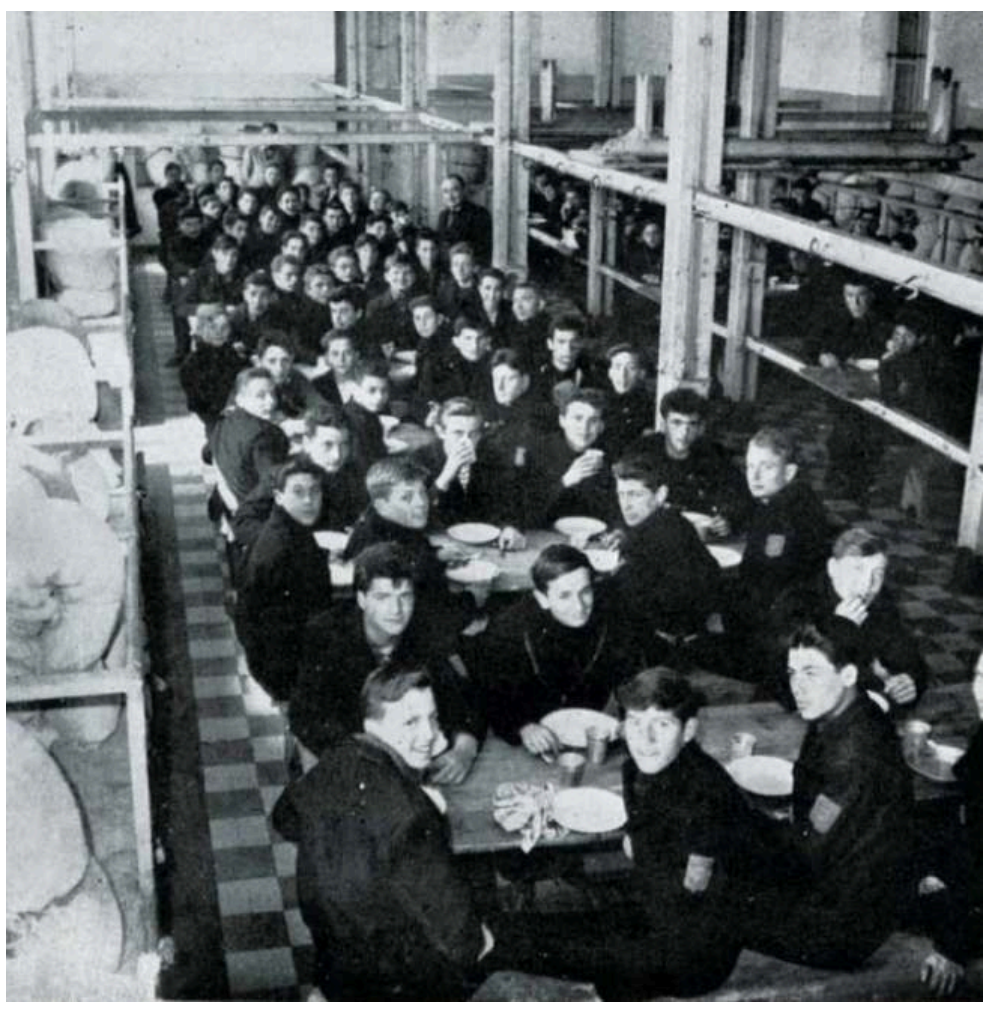

Illustration 8

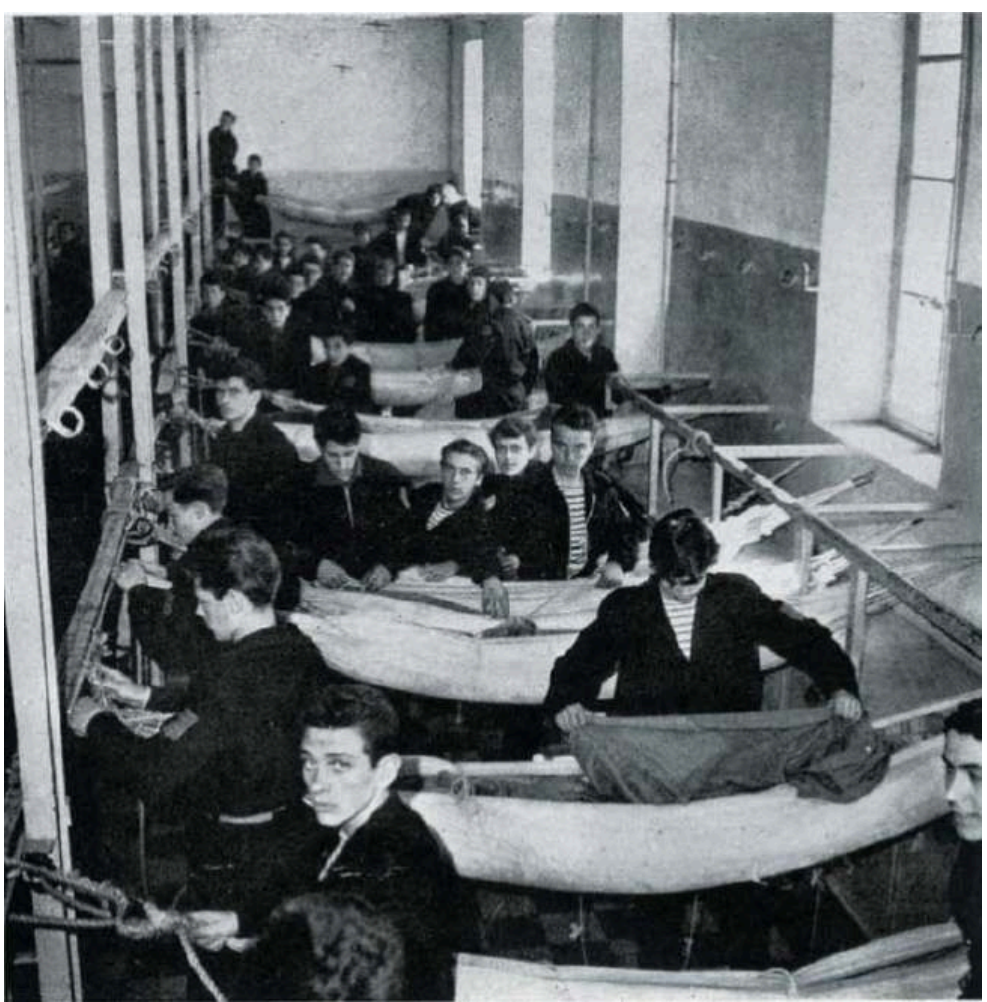

Le commentaire ajouté par le reporter concernant l'ambiance au moment du repas : « Au réfectoire, la gaieté est de tradition », n'est pas spontanément manifeste sur l'image.

Source : Revue Sillage, $n^{\circ} 6$ et 7 , nd. 
S'il faut recourir à des photographies prises lors d'un reportage sur l'École (évoqué plus haut) pour pouvoir se représenter l'espace et surtout l'importance de l'effectif, le souvenir des lieux reste particulièrement vivace, comme l'atteste ci-dessous le plan reproduit (Illustration 9). On notera quelques détails portés sur le plan qui n'apparaissent pas sur les photographies: «carré des maîtres, office du carré, porte condamnée par vents d'est!»

Illustration 9 : plan dessiné du bâtiment principal

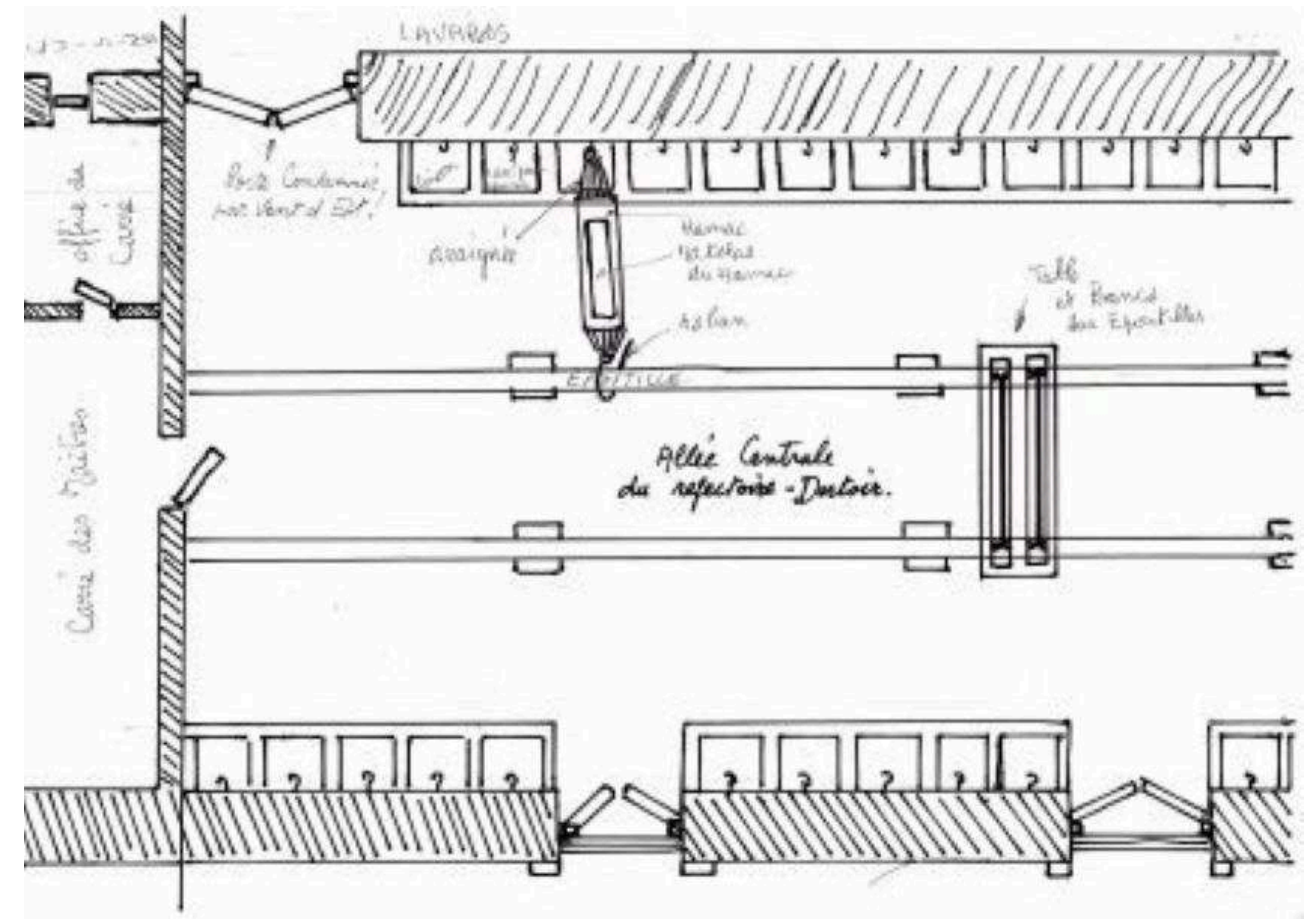

Dessin P. Rouché (Promotion 1953-1954).

\subsection{Le canot, une organisation efficace sur mer et sur terre}

Le « dispositif du canot » constitue également un aspect de disciplinarisation des corps dans l'espace mais il renvoie simultanément à la volonté de rendre productive une pédagogie à travers la constitution d'un collectif pertinent. Il fonctionne comme une métonymie puisqu'il désigne l'ensemble de l'équipage composant le bateau. Si le canot physique est une structure modulable et polyvalente (utilisable comme un bateau à rames ou un bateau de navigation avec des voiles au tiers), le «canoT $»^{30}$ est une structure stable dans le temps, qui fonctionne comme instance de production et de contrôle intermédiaire. Ainsi, il réalise par rotation quotidienne les corvées d'entretien ou d'approvisionnement :

«À huit heures rassemblement par canot devant la porte principale, envoi des couleurs et activités de formation sauf pour le Canot de corvée de jour, c'est-à-dire désigné pour assurer l'entretien des locaux, réfectoire dortoir, salle d'études, WC et des corvées de cuisine nettoyage des plats et épluchage des légumes, la corvée de vivres consistait à débarquer les denrées et le pain ramenés par un vieux thonier qui transportait aussi le charbon pour la chaudière en hiver. " (PR_Promo 53/54_Témoignage écrit) 
La désignation d'un chef de canot est bien sûr une marque de reconnaissance d'une capacité à exercer un contrôle sur les autres (Illustration 10) et permet de différencier un individu des autres ${ }^{31}$. Le document ci-dessous appartenait à un responsable de canot: son nom en haut de la liste est repérable par la taille des lettres et l'usage des majuscules. Son nom semble "repassé ", ainsi que celui qui figure juste après lui et qui pourrait être son «second». En face des autres noms inscrits les uns sous les autres, des activités (balayage, ajustage, matelotage) ont été pointées au crayon de papier. Cette activité renvoie à l'idée de l'écriture disciplinaire et du "plasma graphique " foucaldien, qui entoure les individus dans le processus quotidien de l'apprentissage.

Illustration 10 : reproduction d'un petit carnet détaillant la composition du canot

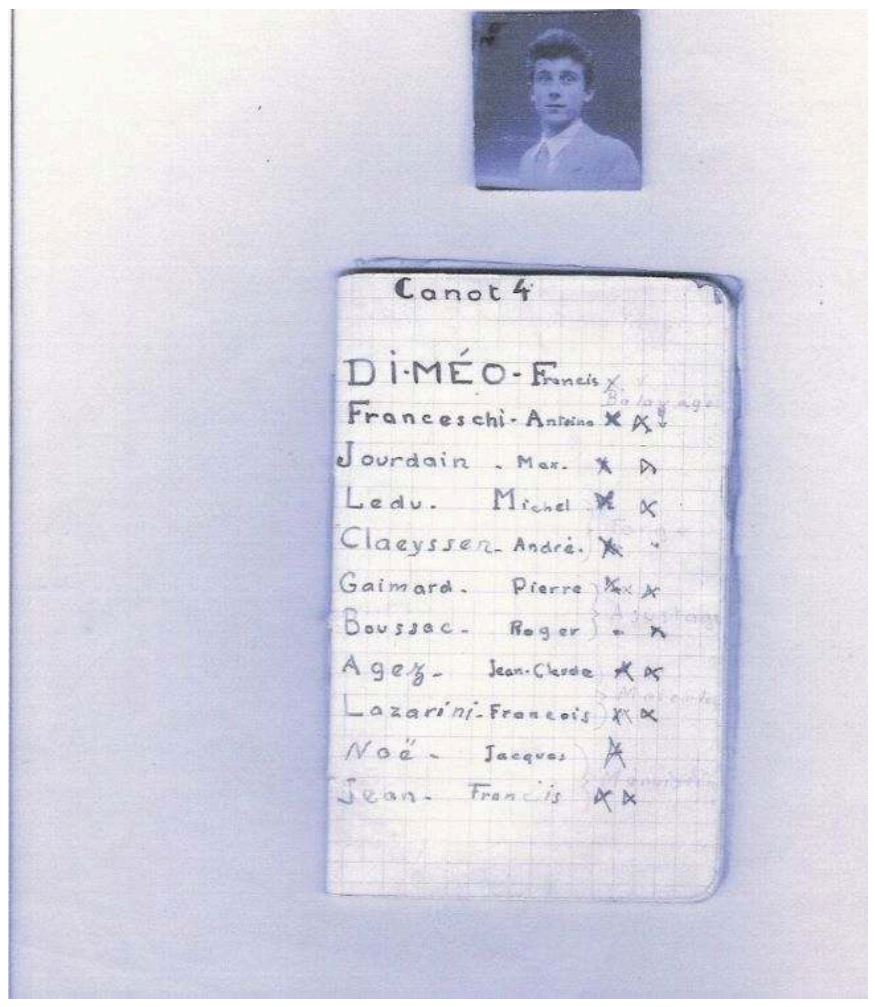

Document personnel F. Di Méo (Promotion 1955-1956).

\subsection{L'emploi (total) du temps}

L'École du Frioul a développé une organisation parvenue à capter presque totalement le temps passé par les élèves sur l'île, qu'il s'agisse du temps scolaire comme de celui qui ne l'est pas. Si le reportage effectué sur place annonce un total de 36 heures, c'est bien sûr en s'en tenant strictement aux matières enseignées. Dans les mémoires, le décompte est largement supérieur. La reproduction d'un cahier sur lequel l'élève a consigné les activités réalisées chaque jour de la semaine permet de distinguer cinq catégories de temps au cours la journée qui fonctionnent en alternance (Illustration 11). Les enseignements pratiques et professionnels prédominent; ajustage, forge, charpentage, matelotage, voilerie.

Les temps de culture générale ou de théorie sont plus limités mais on peut considérer que les séquences d'étude (à raison de 2 ou 3 heures quotidiennes) viennent les 
compléter. Le sport est quotidien; il s'agit d'une heure de natation. Enfin, il faut considérer un dernier temps, celui dévolu aux différentes corvées. Un principe d'équivalence est posé entre temps de formation et corvées puisque chaque jour un "Canot» (cf. ci-dessus) est désigné pour réaliser les corvées de jour et à ce titre n'assiste pas aux enseignements.

Illustration 11 : reproduction d'un cahier et contenu retranscrit et commenté par l'auteur

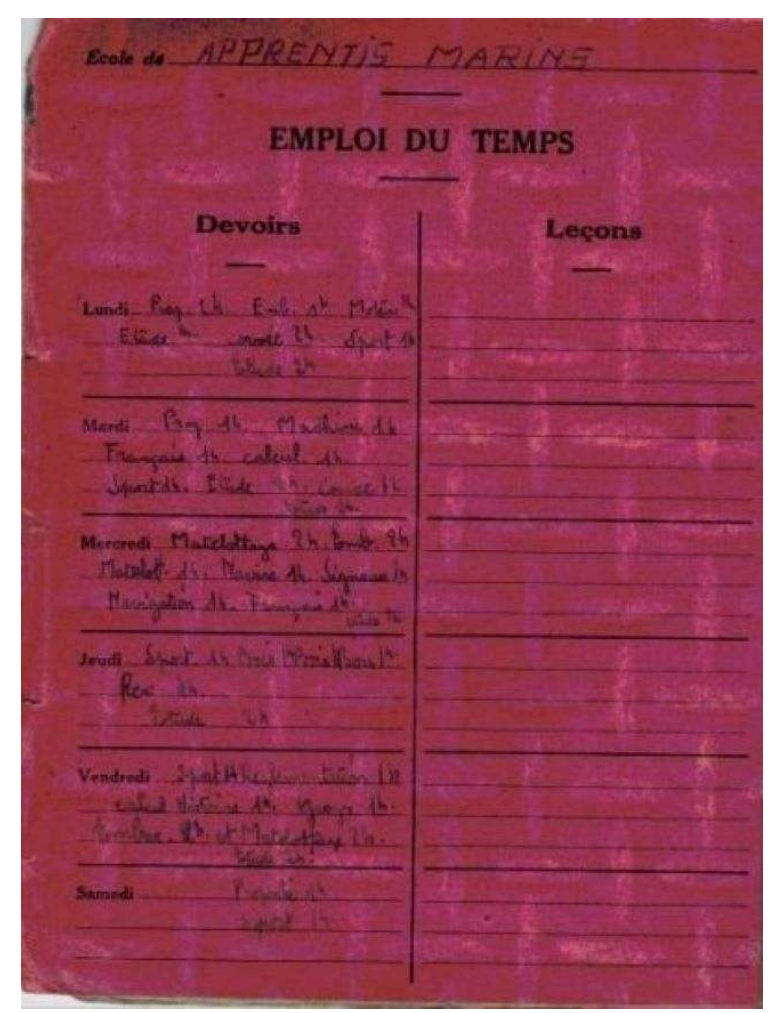

Emploi du temps :

Lundi : propreté $2 h$, embarcation $1 h$, cours moteur $1 h$, étude $1 h$, corvées $2 h$, sport $1 h$, étude $2 h$.

Mardi : propreté $1 \mathrm{~h}$, cours machine $1 \mathrm{~h}$, français $1 \mathrm{~h}$, calcul $1 \mathrm{~h}$, sport $1 \mathrm{~h}$, étude $2 \mathrm{~h}$, corvée $1 \mathrm{~h}$, étude $2 \mathrm{~h}$. Mercredi : matelotage $2 h$, embarcation $2 h$, cours navire $1 h$, cours signaux $1 h$, cours de navigation $1 h$, français $1 \mathrm{~h}$, étude $1 \mathrm{~h}$.

Jeudi : sport $1 \mathrm{~h}$, cours de charpentage $3 \mathrm{~h}$, cours d'ajustage $4 \mathrm{~h}$, étude $2 \mathrm{~h}$.

Vendredi : sport $1 \mathrm{~h}$, cours de réglementation $1 \mathrm{~h}$, calcul $1 \mathrm{~h}$, géographie $1 \mathrm{~h}$, embarcation $2 \mathrm{~h}$, matelotage $2 h$, étude $2 h$.

Samedi : Propreté 1 h, sport $1 \mathrm{~h}$.

Cela nous faisait des semaines de 52 heures d'activités... !!

Coll. P. Rouché (Promotion 1953-1954)

Il faut également souligner que le Frioul à l'époque n'est pas alimenté en eau potable et que l'eau est livrée chaque mois par un bateau citerne de 300000 litres. Les corvées d'eau, de ravitaillement, de nettoyage ou d'entretien des affaires personnelles sont réalisées par les élèves eux-mêmes. Enfin, sans être désigné comme "corvée " par l'institution, monter la garde est resté pour nombre d'anciens élèves comme une épreuve, la garde de sécurité devant ainsi être effectuée sur des tranches de 2 heures, y compris la nuit.

Par sa situation insulaire, l'École tend à reproduire le principe des conditions de vie à bord où le marin ne dispose que d'un temps personnel extrêmement réduit. Dans une gestion extrêmement serrée du temps - de celui de la journée et de toutes ces activités à celui des neuf mois de la formation -, les élèves font l'apprentissage de la cadence, de 
la répétition, d'une forme d'abolition des saisons (« la natation en hiver comme en été » se souvient un élève), de l'exactitude mais peut-être aussi de l'attente (celui du weekend sans sortie), bref du temps social et moral du marin.

\subsection{La sanction et l'examen comme instruments de discipline} de résultats scolaires, ce qui conditionne la mise en place de mécanismes pour les modeler, les vérifier et éventuellement les corriger. Si le dispositif du canot participe d'une manière de surveillance horizontale et ascendante, il est bien sûr plus discret que le système vertical qui dispose, en plus de l'autorité morale des «instructeurs ", de l'instrument de la sanction. Les anciens élèves ayant rédigé des témoignages écrits ne sont pas très nombreux à décrire les sanctions dont ils ont pu faire l'objet; en revanche, tous les interviewés ont évoqué la rapidité avec laquelle le moindre écart à la règle était assorti d'une punition, le plus souvent une interdiction de sortie le weekend. Un élève relate qu'au cours du premier trimestre (sur neuf mois de formation), il n'a eu aucune permission de sortie. L'évocation et la description de certaines sanctions laissent à penser que derrière l'argument de la fonction éducative, il s'agit surtout d'une mise au travail des élèves au profit de l'institution elle-même, dans des conditions parfois particulièrement précaires. À près d'un siècle d'écart, on retrouve certains traits de l'exploitation des enfants au sein de l'École des Mousses de Marseille (Américi, 2002).

Si les sanctions peuvent être graduées, les incartades individuelles ou collectives qui témoignent d'un goût de l'aventure ou d'une volonté de s'extraire du cadre normatif ne peuvent supporter aucune tolérance.

Instrument emblématique du processus disciplinaire de l'école, l'examen sert le processus de séparation de l'individu du reste du groupe ; il permet le classement pour le temps de l'école mais l'inscrit beaucoup plus durablement encore, dans les documents archivés, les attestations les carrières qu'il permet, les fiertés personnelles qu'il produit. Ceci est d'autant plus important qu'à niveau de qualification équivalent, il existe une hiérarchie des métiers auxquels préparent les différentes spécialités de formation.

L'idée de compétition n'est pas forcément manifeste dans les discours ou les évocations mémorielles mais le souci de la réussite ou du classement sont clairement exprimés (Illustration 12). Même avec le recul, tous ceux qui ont fini avec un bon classement le signalent dans leur présentation... Un des interlocuteurs rencontrés a conservé le compte-rendu du journal Le Marin (hebdomadaire spécialisé des gens de mer) à l'occasion de la fermeture de l'École au début de l'année 1962. Ce reportage évoque la remise des diplômes et des prix, présidée par l'administrateur en chef de Marseille et pour chacune des spécialités (section pont, section machine) classe par ordre de mérite meilleurs élèves, indiquant leur nom, prénom et moyenne générale. 
Illustration 12 : carnet de notes et attestation de réussite à l'examen du CAP dans la spécialité ADSG.

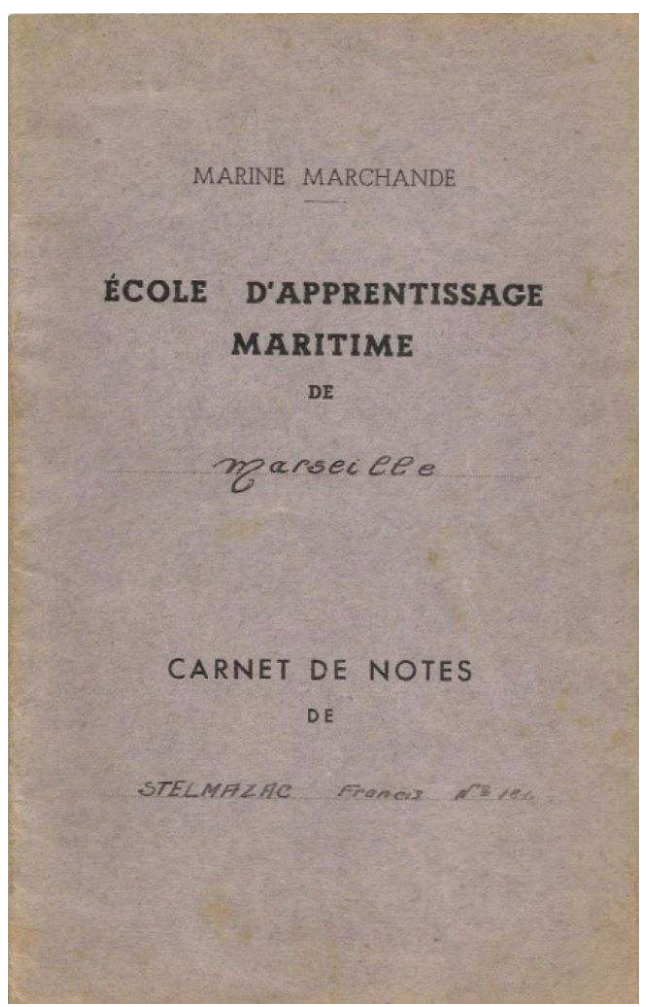

Document personnel F. Stelmaszack

Attestation de réussite à l'examen du CAP dans la spécialité ADSG

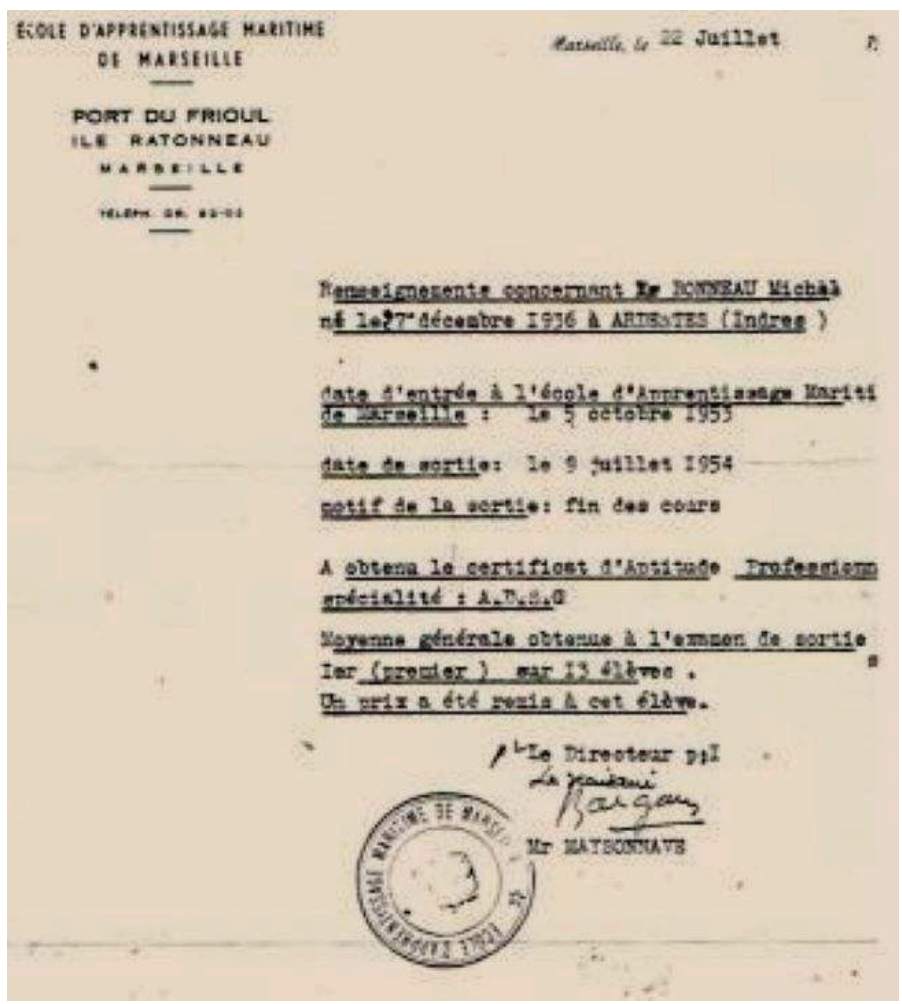

Document personnel M. Bonneau 
Si les besoins en personnel navigant sont encore considérables à cette période, les élèves qui ne peuvent se prévaloir de relations personnelles pour entrer dans les compagnies maritimes savent que celles-ci sont en contact direct avec les écoles. Un interviewé, diplômé en 1956, relatait que le premier bateau des Messageries maritimes sur lequel il avait embarqué avait recruté six mousses ou novices «du Frioul»; l'appréciation d'un directeur couplée à de bons résultats académiques peuvent faire une différence en début de carrière.

\section{Réenchanter le Frioul : de l'enfant au marin et retour}

À lire les rares reportages consacrés à l'École du Frioul, celle-ci n'a pas cherché à masquer le caractère extrêmement sévère de son fonctionnement et de ce point de vue, on est loin de l'évocation qu'en donne pour la même époque l'ancien directeur d'une école bretonne (Wadoux, 1998). En qualifiant de "paternelle» la posture de commandement adoptée par le directeur de l'École, le reporter de la revue Sillages pointe une dimension quelque peu sous-évaluée dans l'approche de certaines formations professionnelles, à savoir la demande des familles d'une prise en charge autant morale que professionnelle de leurs enfants. Dans le cas présent, cette question semble par construction malaisée à saisir dans les témoignages écrits mais elle a été clairement énoncée dans un des entretiens :

« Pour moi ça s'est fait tout différemment, mon père était paysan et ça se passait assez mal à la maison, il était très dur et une fois, un de ses copains lui avait dit 'pour le mater [ton fils] tu devrais l'envoyer là-bas au Frioul'. Et c'est comme ça que je me suis retrouvé dans cette école. Moi je n'étais pas forcément contre, pourvu que je quitte la maison et que je puisse partir de la ferme. Alors j'étais l'année 55 56 et je peux vous dire que c'était cette année où il a fait si froid en France et nous, là-bas, l'eau était dans des citernes et ils nous faisaient casser la glace, pour qu'il y ait de l'eau.» (JFi_Promo 55/56_Entretien. JFi a réalisé une bonne partie de sa carrière maritime dans la navigation au long cours, à la compagnie des Messageries maritimes.)

51 On peut souligner comment perdure dans l'imaginaire parental la fonction d'encadrement réalisée par l'École des mousses de Marseille. Si la référence au travail d'éducation d'une enfance supposée indocile et sauvage (Américi, 2002) peut encore être envisagée dans la période considérée, l'hypothèse que d'autres arrachements sont en jeu, notamment celui des populations rurales conduites à se transformer dans le processus de modernisation dans la France des années cinquante, mérite d'être considérée. Alors qu'une partie des élèves est entrée à l'École en raison d'un lien familial avec la marine (pupilles ou enfants d'inscrits maritimes) - et a déjà effectué quelques années de "préapprentissage maritime ", à l'École Courbet de Marseille ou dans une autre école des mousses -, pour les autres la socialisation au sein de l'École constitue une épreuve vécue différemment suivant qu'elle traduit un projet familial ou individuel d'une future vie maritime. En voici deux expressions radicalement opposées :

«Ah, Le Frioul ! J'avais à peine 14 ans quand j'ai foulé aux pieds les premières caillasses de l'EAM, la terre de ma campagne natale, entre Hyères et Toulon, collait encore à mes godasses. Dur, dur de devenir marin... Dur, dur de vivre sur ces cailloux. Comme pour les tranchées de 14/18, le meilleur souvenir est probablement le jour de la quille, et celui de notre jeunesse passée... [...] J'ai haï ce lieu, je l'ai vécu comme une injustice, quelle avait été ma faute?» (YO7_Promo 
57/58_Témoignage écrit. YO a poursuivi ses études dans une autre EAM puis après 5 années de navigation dans différentes compagnies maritimes, il s'est orienté vers l'École nationale supérieure maritime pour y suivre un brevet de mécanicien. Il entreprend par la suite des études d'électrotechnique.)

"Je venais des Deux-Sèvres, je ne connaissais même pas la mer mais ma mère avait divorcé et on était parti s'installer en Corse et ce qui m'avait tout de suite frappé c'était le fait d'avoir pris le bateau pour aller en Corse. Le Sampiero Corso, un vieux paquebot qui faisait Marseille Ajaccio. Je sortais de ma campagne charentaise, alors la mer je l'avais très peu vue et tout de suite, ça a été le coup de foudre, j'ai voulu faire marin, voilà. Maman était divorcée alors quand je lui ai dit que je voulais partir dans la marine, elle a dit 'je ne ferai pas les papiers' et moi j'ai dit 'je les ferai et je les signerai' (Rires) Ah oui, j'avais 15 ans à l'époque mais c'était comme ça et quand elle a compris que je n'avais rien d'autre dans la tête, et bien, elle a accepté et puis voilà, et je suis parti donc au Frioul.» (NF_Promo 61/62_Entretien. Novice machine à la sortie de l'École, NF a réalisé une carrière de sept ans dans la marine avant d'entamer une reconversion dans la gendarmerie.)

Qu'il s'agisse de la description objective de certains fonctionnements ou de l'expression de souvenirs relatés à un âge déjà avancé de la vie, le temps passé à l'École apparaît comme un rite de passage (Van (Gennep, 1987 [1909]). Cette transition s'opère par l'apprentissage d'un vocabulaire spécifique ${ }^{32}$, l'arrachement au premier cercle de la socialisation, celui de la famille, et plus particulièrement la rupture avec ses figures féminines $^{33}$, l'appropriation de valeurs professionnelles cardinales telles que l'endurance, l'isolement, le confinement, la mesure du risque, le respect de la hiérarchie (Benjamin, 1970). Dans l'enseignement étudié, les mises en situation fonctionnent comme des épreuves; le projet pédagogique est le plus souvent rabattu sur l'affirmation réitérée que la mission de l'École est de transformer l'individu et de le sortir de sa condition d'enfant pour celle de marin.

«Combien de fois on nous a dit 'vous rentrez chez nous vous êtes des enfants, vous sortez de chez nous vous êtes des hommes, on veut faire de vous DES HOMMES' ça c'est un point qui m'est toujours resté. [...] C'était un peu les méthodes de cette époque-là aussi, mais attention, les instructeurs étaient sévères mais pas méchants non plus, c'était plutôt sévères et intransigeants, c'était... il fallait bien faire et c'était comme ça, mais bon, après pour toute ma vie ça m'a resté pour toute ma carrière et pour ma vie future; je voudrais bien que mes petits-enfants soient comme ça. » (NF_Promo 61/62_Entretien)

Dans les souvenirs et témoignages, les interactions avec les adultes instructeurs semblent avoir été limitées à l'apprentissage de gestes et de techniques dans un rapport d'obéissance dû essentiellement à l'âge et à la carrière ${ }^{34}$. En revanche, les échanges entre élèves leur semblent aujourd'hui déterminants, pour l'apprentissage du travail en équipe, la solidarité mais aussi l'émulation ou encore la gestion de la peur ou des conflits. Ensemble, les élèves sont sortis de l'enfance. Les photographies qui les représentent dans des configurations amicales à géométrie variable donnent à voir des poses et des attitudes qui signalent que la sortie ou l'entrée dans l'âge adulte ne se réalisent pas au même rythme. En voici quatre exemples (Photographies 6 à 9) où tous les élèves appartiennent à la dernière promotion sortie en décembre 1961. 
Photographies 6 et 7 : différentes expressions des amitiés juvéniles

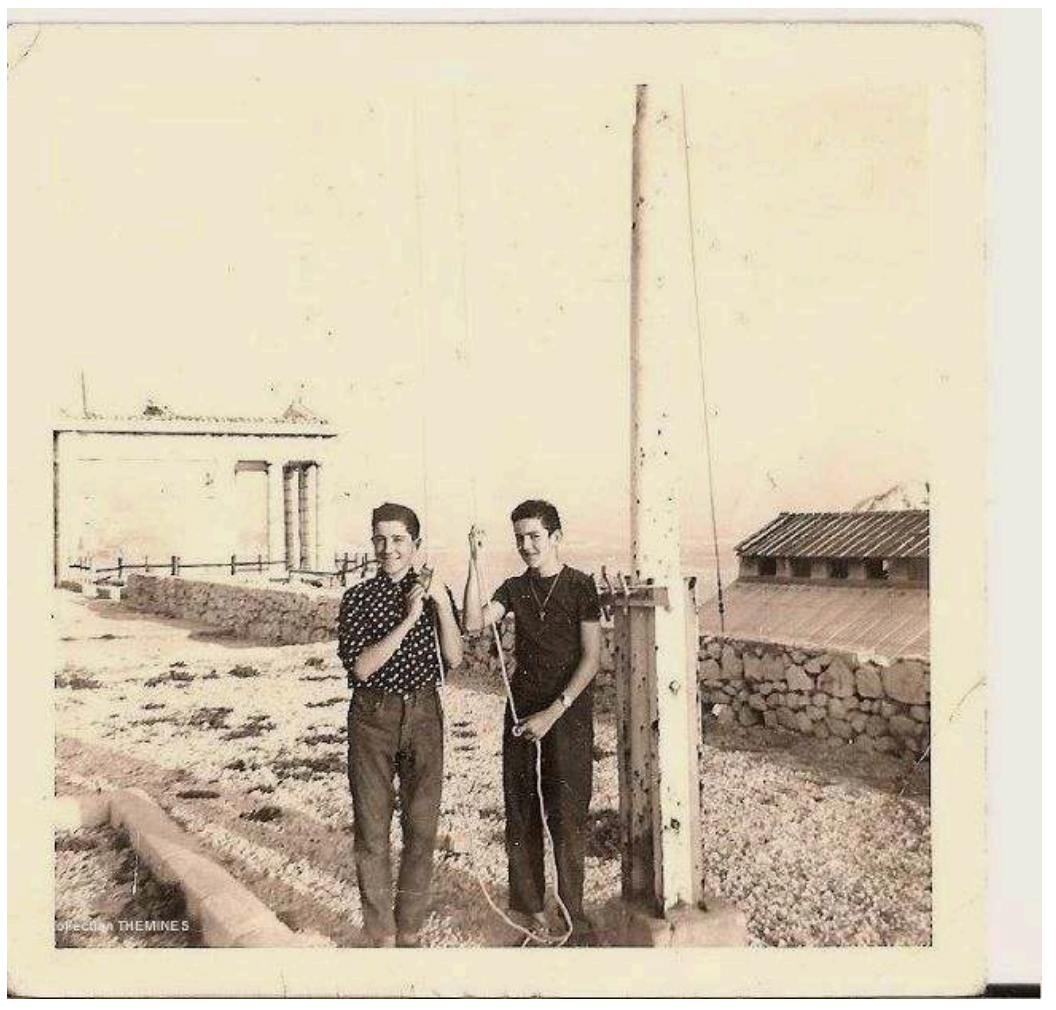

Coll. Themines (Promotion 1961-1962)

Photographie 7

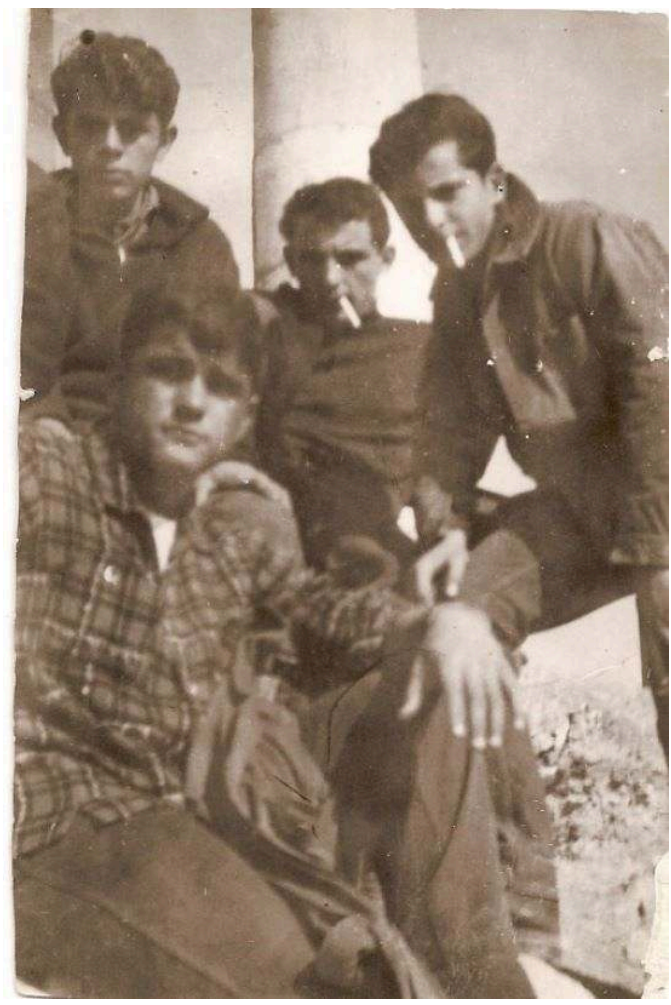

Le titre donné à cette photographie est « Les durs de Marseille » Coll. Bertalmio (Promotion 1961-1962) 
Photographies 8 et 9 : présentation de soi et du groupe en dehors de l'école

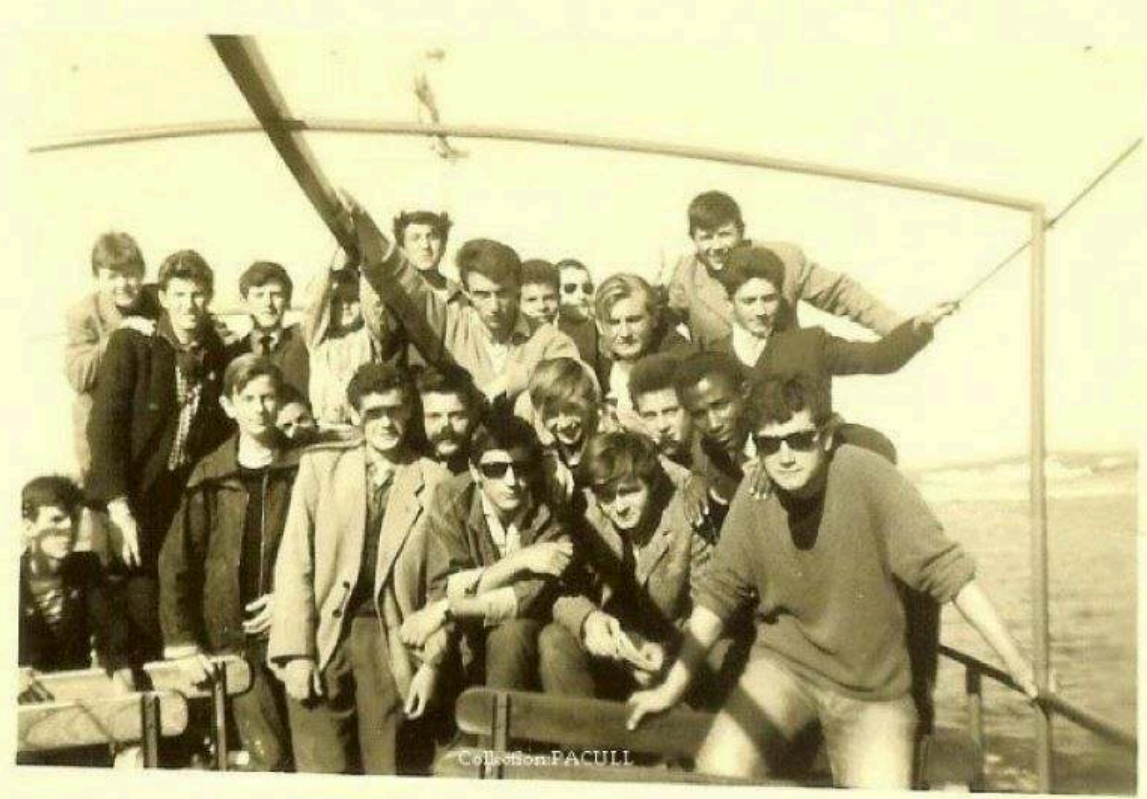

En voyage organisé à l'étang de Berre ou en « liberté » sur la Canebière, le choix du vêtement fait toute la différence.

Coll. Y. Pacull (Promotion 1961-1962) 


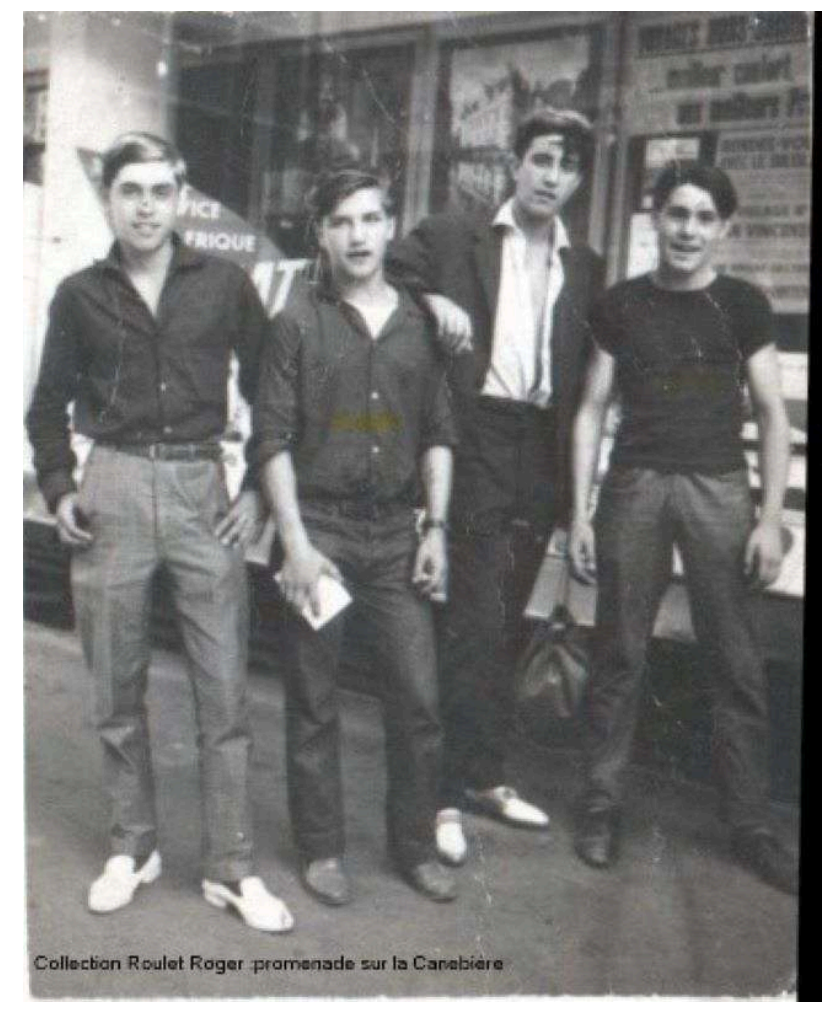

Coll. R. Roulet (Promotion 1961-1962).

54 Les Marseillais ne sont pas forcément majoritaires au sein de l'École mais ils ont un statut particulier aux yeux des autres. Ils sont considérés comme plus matures par leurs camarades car eux connaissent déjà la ville port et ses dangers, élément important de la vie maritime. La socialisation au sein du groupe des pairs prend tantôt la forme de rites initiatiques des plus âgés vis-à-vis des plus jeunes, d'affirmation d'une solidarité voire de transgression de la règle :

« Donc le soir après les cours quartier libre sans quitter l'école, mais comme il n'y avait pas de clôtures l'île nous appartenait: les casemates des allemands étaient intactes ainsi que les canons anti-aériens et l'on se faisait un plaisir de tout faire fonctionner jusqu'à ce qu'une jeep de la marine nous fasse déguerpir, puis le lendemain, le sermon du directeur !» (AR2_promo 51/52. AR a travaillé pendant 14 ans comme agent du service général à la compagnie des messageries maritimes jusqu'à la fermeture de l'entreprise, puis se reconvertit comme soudeur et travaille aux chantiers de La Ciotat.)

Si les lieux ont une importance dans l'existence et le fonctionnement du groupe, il faut signaler le rôle éminent (à double titre) de la chapelle. Un élève de 1956 dit "on l'appelait notre place d'armes ». Le bâtiment est situé sur un promontoire ${ }^{35}$. Investi par le groupe des élèves, le lieu confère symboliquement à ceux-ci une autre place que celle à laquelle la structure très hiérarchisée de l'École et de la marine les assigne. D'ailleurs, si de manière attendue, les élèves s'y retrouvent pour fumer des cigarettes en cachette, elle se révèle aussi un lieu de formation d'une essence exceptionnelle :

"Quand on avait du temps, on allait à la chapelle et la Chapelle c'était sur la colline et quand un bateau arrivait, on avait un jeu : être le premier à trouver quel bateau c'était, avant même de pouvoir lire, et après quand on avait vu le nom, quelle compagnie? et d'où il venait, c'était notre truc, et les bateaux qui passaient de 
l'autre côté, parce que les bateaux qui passaient par la passe Nord passaient obligatoirement à l'ouest et quand on les voyait de l'autre côté, on savait que ceuxlà allaient loin, c'était ceux qui allaient loin, alors on essayait, parce que des fois quand vous avez le soleil couchant, vous ne voyez rien, vous ne voyez que l'eau, vous voyez l'ombre, la silhouette du bateau, vous ne voyez pas quel bateau, alors il fallait trouver quel bateau c'était et où il allait, et c'est pour ça que je vous dis « tous les marins sont bons en géographie » et moi c'était mon truc et de l'autre côté, il y avait encore la desserte du Maghreb, il y avait énormément de bateaux qui passaient, il y en avait des bateaux, le Marseille, l'Oran, et chaque bateau avait une forme différente et notre truc c'était de reconnaitre celui qui passait. " (ARi_Promo 61/62_Entretien. ARi a travaillé comme marin à la machine pendant deux années avant de devoir arrêter le métier pour motifs personnels et s'orienter vers l'artisanat.)

\section{Conclusion}

La production d'une mémoire des lieux de formation se trouve aujourd'hui transformée par l'usage de l'internet. Dans le cas présent, les anciens élèves eux-mêmes ont contribué directement à en restituer une forme singulière. L'analyse du matériau qui en est issu - composé d'écritures (ordinaires mais extraordinaires) et d'images photographiques puis complété d'entretiens - a permis de rendre compte d'une réalité de l'enseignement maritime qui parait assez éloignée de celle qu'en proposent les institutions elles-mêmes ${ }^{36}$. Elle contraste aussi par exemple avec d'autres récits biographiques, comme celui de P. Wadoux (1998), qui après avoir été ancien matelot puis capitaine au long cours, était devenu, à la fin des années 1950, directeur d'une EAM à Étel. Les évocations par ce dernier de son souci de la pédagogie, de son soin pour l'équipement de l'école (ateliers ou bateaux) ou de son intérêt pour les dimensions sociales et culturelles à travers l'organisation des temps de loisirs semblent assez peu convergentes avec les témoignages des anciens élèves. Au contraire, ce matériau met en avant une dimension dramatique qui se joue autour de la formation, dimension renforcée ici par la nature de l'activité professionnelle préparée, la période des années 1950 mais aussi le territoire de l'école et sa particularité insulaire.

Si préparer les futurs marins aux dangers de la mer a été un des objectifs des premières écoles de pêche, le risque est resté une réalité professionnelle. Enseignée théoriquement aux élèves, la violence de la mer semble s'imposer plus ou directement dans les expériences individuelles. C'est ce que traduit dans son témoignage un ancien élève de l'École évoquant un de ses amis « mort à Hambourg, entraîné par la chaîne de mouillage et tué en arrivant à l'écubier » et dont une des navettes desservant le château d'If ${ }^{37}$ porte le nom.

Le processus de transformation d'une population juvénile en futurs marins peut aussi être qualifiée d'épreuve vécue dans le temps de la formation; un nombre important de témoignages vont dans ce sens. Si le renouveau de la marine française est alors en jeu à l'époque, l'enseignement corporatiste au principe des EAM tend à privilégier les méthodes assez traditionnelles; les instructeurs tendent visiblement à reproduire chez les élèves les modèles professionnels qu'ils ont eux-mêmes expérimentés, en leur inculquant une morale et d'une discipline de travail. Il est probable que la localisation spécifique de l'École de Marseille a favorisé ce type de disposition, tout comme les élèves ont pu aussi trouver sur l'île un territoire privilégié pour intégrer rapidement des codes et une sociabilité professionnels. 
On peut aisément convenir que les anciens apprentis marins engagés dans cette aventure qui a consisté à faire revivre l'École représentent un sous-ensemble limité et biaisé de l'ensemble des élèves qui l'ont fréquentée. Pour autant, ils n'agissent pas en entrepreneurs de la mémoire. Il faut en effet rappeler qu'ils ont été sollicités par un de leurs pairs pour livrer à travers l'écriture un point de vue sur une période très courte mais objectivement déterminante de leur vie. Si l'exercice ne prend pas les formes canoniques du journal intime - dont P. Lejeune rappelle qu'il est au XIXe une invention de l'institution scolaire elle-même (Rochefort \& Houbre, 1996) ${ }^{38}-$, il oblige à une réflexion sur l'après-coup et pose en creux la question des autres vies possibles. Voilà sans doute pourquoi les interlocuteurs rencontrés lors des entretiens ont insisté sur le fait qu'ils n'avaient pas de regret, alors même que la question n'a jamais été évoquée en ces termes. En définitive, le seul point commun à tous les témoignages réside dans la volonté d'exprimer une appréciation positive de cette époque («Voilà ce qui me reste comme bons souvenirs du Frioul»). Mais cette rhétorique légèrement conventionnelle ne doit pas faire oublier qu'elle est le produit d'un travail mémoriel dans lequel les individus introduisent de la rationalisation pour reconstituer la continuité d'un parcours (Bourdieu, 1986). C'est ainsi que tous ont aussi évoqué de manière détaillée leurs premières expériences professionnelles de marins, citant le nom des différents bateaux sur lesquels ils ont embarqué, avec les photographies de ceux-ci. Le bateau et son image agissent alors comme une signature personnelle, trace vivante du passage et de la vie au Frioul.

\section{BIBLIOGRAPHIE}

Américi L. (2002), « La chambre de commerce de Marseille et la main-d'œuvre enfantine : l'École des mousses (1839-1901) ", in Caty R. (dir.), Enfants au travail. Attitudes des élites en Europe occidentale et méditerranéenne aux XIX ${ }^{e}$ et XX $X^{e}$ siècles, Aix-en-Provence, Publications de l'Université de Provence, p. 201-217.

Barroero D. (1995), L'enseignement technique à Marseille de 1815 aux années 1960. Tome 2 : Après 1939. Thèse de doctorat de l'université de Provence. Aix-Marseille I.

Biget D. (2005), « Des écoles de pêche aux lycées maritimes et aquacoles », Techniques et culture, $\mathrm{n}^{\circ} 45, \mathrm{MSH} / \mathrm{CNRS}$, janvier-juin 2005, p. 39-58.

Biget D. (2009), L'enseignement professionnel des pêches maritimes en France (1895-2007), Paris, L'Harmattan.

Biget D. (2010), Écoles de pêche, EAM et EMA, lycées professionnels maritimes - 115 ans d'histoire de l'enseignement professionnel maritime en France, La Faouët, Liv'Éditions.

Bourdieu P. (1986), «L'illusion biographique ", Actes de la recherche en sciences sociales, vol. 62-63, p. 69-72.

Cabantous A. (1993), « Apprendre la mer : remarques sur des mousses à l'époque moderne », Revue d'histoire moderne et contemporaine, tome $40, \mathrm{n}^{\circ} 3$, Apprentissages $\mathrm{XVI}^{\mathrm{e}}-\mathrm{XX}^{\mathrm{e}}$ siècles, $\mathrm{p}$. 415-422. 
Cassagnou B. (2002), Les grandes mutations de la marine marchande française (1945-1995). Volume I. Paris, Comité pour l'histoire économique et financière de la France. Ministère de l'Économie, des Finances et de l'Industrie.

Chaumette P. (1993), Le contrat d'engagement maritime, Paris, CNRS Éditions.

Dubet F. (2014), « Foucault et l'école : une absence d'usage », in Oulc'Hen H., Usages de Foucault, Paris, Presses Universitaires de France, « Pratiques théoriques », 231-250.

Duval M. (1998), Ni morts, ni vivants : marins! Pour une ethnologie du huis clos, Paris, Presses universitaires de France.

Elias N. (2003), «Études sur la genèse de la profession de marin », Les Champs de Mars, 13, 1er sem., p. 5-34.

Faget D. (2011), Marseille et la mer. Hommes et environnement marin (XVIII ${ }^{e}-X X^{e}$ siècle), Rennes, Presses universitaires de Rennes, en coédition avec les Presses universitaires de Provence. Foucault M. (2013), La Société punitive. Cours au Collège de France (1972-1973), Paris, Le Seuil. Gardiner R. et Greenway A. (ed.). (2000), The Golden Age of Shipping: The Classic Merchant Ship 1900-1960, New York, Book Sales.

Gras P. (2010), Le temps des ports. Déclin et renaissance des villes portuaires (1940-2010), Paris, Tallandier.

Halbwachs M. (1994 [1925]), Les cadres sociaux de la mémoire, Paris, Albin Michel.

Kennerley A. (2008), “Aspirant navigation: training and education at sea during commercial voyages in British merchant ships C. 1850 to 1950", The Great Circle, vol. 30, n². 41-76.

Lambert G. \& Lembré S. (2017), « L'enseignement technique en ses lieux. Conception, édification et usages (XIXe-XXe siècles) », Histoire de l'éducation, n¹47, 9-35.

Le Doaré A. (2000), La naissance des prêtres-marins (1938-1955). Juxtaposition progressive de modèles missionnaires de l'Église catholique dans le monde maritime en France au XX $\mathrm{X}^{e}$ siècle, Villeneuve-d'Ascq, Presses universitaires du Septentrion.

Marnot B. (2014), « Les ports français et la mondialisation au XIXe siècle ou l'émergence de trois modèles de croissance régionaux ", Monde(s), 2, nº, p. 195-222.

Paradeise C. (1984), « La marine marchande française : un marché du travail fermé ? ", Revue française de sociologie, 25-3. 352-375.

Régaudat B. (2005), «La Chambre de commerce de Marseille et l'enseignement maritime du XIXe siècle à la Seconde Guerre mondiale », in Charmasson T. (dir.), Formation au travail, enseignement technique et apprentissage, Paris, Éditions du CTHS.

Régnault R. (1998), « Rapport d'information fait au nom de la commission des Finances, du contrôle budgétaire et des comptes économiques de la Nation sur la mission de contrôle relative à la situation de l'enseignement maritime en France », Session ordinaire du Sénat, nº536.

Robert A. D. (2010), L'École en France de 1945 à nos jours, Grenoble, Presses universitaires de Grenoble.

Rochefort F. et Houbre G. (1996), « Témoignage : Philippe LEJEUNE », Clio. Histoire, femmes et société, 4, p. 11-14.

Segrestin D. (1985), Le Phénomène corporatiste. Essai sur l'avenir des systèmes professionnels fermés en France, Paris, Fayard, Collection : Fondation Saint-Simon. 
Troger V. (1993), « Du modèle allemand à la scolarisation à plein temps des apprentissages : le tournant des années 1940-1950 ", Revue d'histoire moderne et contemporaine, tome 40, n³, Juilletseptembre. Numéro thématique Apprentissages XVI ${ }^{\mathrm{e}}-\mathrm{XX}^{\mathrm{e}}$ siècles, p. 490-502.

Troger V. (2002) « L'identité perdue des enseignements techniques », in Moreau G. (coord.), Les patrons, l'État et la formation des jeunes, Paris, La Dispute.

Van Gennep A. (1987 [1909]), Les rites de passage, Paris, Éditions A\&J Picard, Collection : Picard Histoire.

Wadoux P. (1998), Avant d'être matelot! De l'art de former des mousses et des novices sur le plancher des Vaches, Lorient, Sel-Edit'.

\section{NOTES}

1. Ensemble de quatre îles situé dans la baie de Marseille, à une demi-heure de bateau du VieuxPort.

2. Il s'agit de la dernière promotion scolarisée sur l'île. L'Armée ayant rendu le terrain à la Ville de Marseille, l'École a quitté les lieux en janvier 1962 pour être installée dans des bâtiments neufs, à proximité de l'actuelle École nationale de la marine marchande, quartier de la Pointe rouge à Marseille.

3. M. Barbaroux est non seulement plus âgé que ses interlocuteurs mais surtout il y a avec eux, une distance sociale du fait de son activité de commandant.

4. http://frioul-nouveau-regard.com/2019-art-et-culture/histoire-des-iles-du-frioul/4-destemoignages-vecus/. Sur le site de l'association ne figurent plus que deux témoignages; pour l'ensemble des contributions, se reporter au site personnel de M. Barbaroux: http:// andre.barbaroux.free.fr/

5. Largement popularisé par les sites internet spécialisés dans la production d'une remémoration des amitiés scolaires.

6. C'est en découvrant ce premier matériau que m'est venue l'idée de l'article. Je remercie ici M. Barbaroux pour m'avoir communiqué de nombreuses autres photographies et m'avoir permis de contacter puis d'interviewer certains anciens élèves.

7. Le terme d'image est pris ici dans une acception la plus large : mentale, sociale, renvoyant à des représentations aussi bien matérielles que virtuelles ou discursives.

8. Les écoles d'apprentissage maritime constituent la forme génétique des écoles maritimes et aquacoles (1985) devenues en 2001 les lycées professionnels maritimes.

9. Dans la Marine, l'âge détermine une terminologie propre des jeunes marins et une différenciation de statut, sans renvoyer pour autant à qualifier les différents stades de la carrière : le mousse est le plus jeune tandis que le novice a plus de 16 ans. Cette distinction correspond à la période étudiée car les différentes appellations et leurs significations socioprofessionnelles ont évolué dans le temps (Cabantous, 1993, Kennerley, 2008).

10. Norbert Elias (2003) voit la profession de marin et l'étude de sa genèse comme un cas emblématique des transformations sociales globales et de la nature des relations entre groupes sociaux.

11. Sur l'influence de l'Église catholique et des congrégations dans la construction de l'enseignement maritime, cf. Le Doaré, 2000.

12. Cette association dont le secrétaire général est alors à Paris et le secrétaire adjoint à Marseille, représente en fait les intérêts patronaux du secteur sous le contrôle du commissaire du gouvernement. 
13. En témoignent les photographies de quelques-unes d'entre elles reproduites dans l'ouvrage de Denis Biget (2011).

14. En 1928, le ministère de l'Instruction publique avait déjà exprimé l'intention d'intégrer l'enseignement des pêches dans l'enseignement primaire et à en contrôler la formation des maîtres (Biget, 2010, p. 83).

15. Une circulaire de 1941 accordait à tout organisme professionnel ou collectivité locale le droit de créer et gérer son école (Biget, 2005).

16. Le ministre de la marine marchande de l'époque est alors Gaston Deferre qui a déjà été maire de Marseille de 1944 à 1946.

17. Géré par l'administration maritime, le livret maritime témoigne certes de l'intervention de l'État vis-à-vis de la profession mais aussi des mécanismes corporatistes ayant permis aux patrons et salariés de fermer le marché du travail (Chaumette, 1993).

18. Ou d'autres formes de promotion, comme le reportage réalisé à l'École des mousses de Brest en 1961 pour le Journal télévisé en octobre 1961 : https://m.ina.fr/video/CAF97038084/1-ecoledes-mousses-de-brest-video.html

19. L'affiche de gauche est présentée sur différents sites d'enchères, signalant : « affiche originale entoilée, Litho François Beaudoin (années 50)».

20. D. Biget (2010, p. 142-147) évoque les «éclatés » de navires, utilisant un processus similaire pour les planches d'enseignement des classes de l'apprentissage maritime.

21. À l'exception d'une école de pêche créée à l'initiative de la Ville à la fin du XIX ${ }^{\mathrm{e}}$ siècle (Faget, 2011).

22. Le petit Marseillais, 4 Avril 1942. La ville a été retenue par l'Amirauté comme un lieu pertinent pour construire « un enseignement de qualité » (cf. la correspondance entre les responsables de la chambre de commerce de Marseille avec les autorités de l'époque, Archives MJ8.43.3 de la CCCM).

23. Indépendamment de la familiarité avec l'outil informatique qui revient parfois en introduction des propos; n'oublions pas que les personnes concernées ont au début de la décennie 2010 entre 65 et 75 ans.

24. Il est possible que le commandant Barbaroux ait sélectionné certaines photographies de groupe qu'auraient pu détenir plusieurs personnes, pour le reste, il semble que chacun des anciens élèves ait eu une grande liberté pour sélectionner les « archives » qu'il souhaitait voir figurer dans l'espace des témoignages.

25. À l'exception d'une photographie d'une séance de ramandage ou de quelques vues des séances de navigation.

26. Les exigences du système professionnel sont d'autant plus élevées qu'il s'agit d'une profession «fermée ». La profession gère par exemple la transition des âges; les mousses âgés de moins de 16 ans, sont situés au premier niveau de la qualification et doivent naviguer pendant un an avant de devenir novices, puis matelots.

27. La revue Sillage est une revue des officiers de la Marine marchande. Le numéro 6-7 (non daté, vraisemblablement aux alentours de 1954) présente un reportage réalisé à Marseille au sein de l'École nationale de la marine marchande, et à l'EAM au Frioul.

28. C'est la seule école à l'époque à l'avoir instituée. On ne peut s'empêcher de faire ici un parallèle avec les propos de proviseurs de lycées professionnels qui revendiquent aujourd'hui comme une mesure radicale et vertueuse le port d'une tenue professionnelle et parlent à ce sujet de « verticaliser » les élèves.

29. Cette photographie est un des rares exemples où l'on voit un élève " en tenue réglementaire » dans l'espace public. En réponse à mes questions sur les photographies personnelles qui auraient pu être prises à l'époque en lien avec l'École, mes interlocuteurs ont évoqué le souvenir de photographes professionnels situés sur la Canebière ou au Vieux-Port.

30. «Prononcer le T de canot » précise un des témoignages. 
31. Toute forme de distinction individuelle exercée par l'institution semble importante à signaler dans l'opération de "présentation de soi » par les anciens élèves. Ainsi, l'un d'eux - dans une évocation pourtant particulièrement elliptique - écrit : «En + des cours, j'étais au service du directeur » (JPV_Promo 60/61_Témoignage écrit)

32. Arrivé deux semaines après les autres, un élève se souvient qu'il est reçu par le surveillant général qui l'initie : « on ne dit pas 'Monsieur', on dit 'Maître' aux instructeurs ».

33. La formation à l'EAM du Frioul est dispensée exclusivement par des hommes.

34. Les échanges sur l'exercice du métier par exemple ne semblent pas avoir été la règle, si ce n'est sur le mode de la mise en garde de la pénibilité et des dangers du métier. Pour les anciens élèves de l'EAM qui ont connu eux aussi par la suite une activité de marins, le discours dissuasif de ces instructeurs moniteurs se rapporte à une période révolue et n'avait pas saisi à quel point le métier de marin était à cette période en pleine transformation (Cassagnou, 2002).

35. Cette situation avait été pensée pour permettre aux équipages restés sur les bateaux en quarantaine de suivre l'office depuis le bateau.

36. Il est intéressant par exemple de voir combien les attitudes prises par les jeunes élèves de l'École des mousses de Brest (cf. ci-dessus) diffèrent de celles observées sur les photographies réalisées dans une beaucoup grande liberté au Frioul.

37. Une des îles du Frioul.

38. Compte tenu de ce qui a été évoqué du modèle d'enseignement, il paraît donc presque logique que la demande soit venue d'un capitaine de navire...

\section{RÉSUMÉS}

Cet article contribue à l'écriture d'une histoire sensible de l'apprentissage maritime, à partir de l'école d'apprentissage maritime de Marseille, installée au cours de la décennie 1950, au large de la ville, sur une des îles du Frioul. En mobilisant une source mémorielle spécifique produite par d'anciens élèves et constituée d'images et de discours sur leur passage à l'École, il s'agit de montrer comment les conditions spatio-temporelles particulières de cet enseignement ont joué pour ces garçons et jeunes hommes comme une propédeutique de la mer. Alors qu'au Frioul il n'existe plus de trace matérielle de l'école et que les derniers élèves l'ont quittée depuis près de 60 ans, comment appréhender une mémoire collective de l'école à partir de la matérialité du lieu, des images et des discours?

This article contributes to the writing of a sensitive history of training and education at sea, from the study of a Maritime Learning School in Marseilles, set up in the 1950s, off the city of Marseilles, on one of the islands of Frioul. By using a memory source produced by alumni and made on one hand by pictures and on the other hand by discourses about their stay with the school, the analysis focuses on how the particular space-time conditions of this teaching played for these boys and young men as a propaedeutic of the sea. Whereas in the island of Frioul there's no physical evidence of the school and more than 60 years after the last pupils left it, how to capture a collective memory of the school from the materiality of the place, the images and the discourses? 
INDEX

Mots-clés : apprentissage maritime, lieu d'enseignement, travail mémoriel, discipline de la formation

Keywords : navigation education, place for teaching, memorialization, training discipline

\section{AUTEUR \\ DOMINIQUE MAILLARD}

Sociologue, chargée d'études au département Formation et Certifications du CEREQ (Centre d'études et de recherches sur les qualifications). Elle a travaillé sur des problématiques variées du système éducatif : fonctionnements des formations doctorales, professionnalisation de l'université, développement de la certification. Depuis quelques années, elle poursuit des travaux autour de la catégorie de décrochage scolaire, des pratiques de prévention et de la question des jeunes non diplômés. Par ailleurs, elle a récemment coordonné avec P. Kergoat un groupe de recherche sur l'apprentissage dont les travaux sur les apprentis paraîtront en 2020. 